\title{
Performance and visceral tissue growth and development of Holstein calves fed differing milk replacer allowances and starch concentrations in pelleted starter
}

\author{
T. T. Yohe, ${ }^{1} \oplus$ T. S. Dennis, ${ }^{2} \odot$ L. N. Buss, ${ }^{1} \odot$ E. J. D. Croft, ${ }^{1}$ J. D. Quigley, ${ }^{2} \odot$ T. M. Hill, ${ }^{2} \odot$ F. X. Suárez-Mena, ${ }^{2} \oplus$ \\ K. M. Aragona, ${ }^{2}$ () A. H. Laarman, ${ }^{3}$ (D) J. H. C. Costa, ${ }^{4}$ and M. A. Steele ${ }^{1 *}$ (i) \\ ${ }^{1}$ Department of Animal Biosciences, University of Guelph, Guelph, ON, Canada N1G 2W1 \\ ${ }^{2}$ Nurture Research Center, Provimi, Cargill Animal Nutrition, Lewisburg, OH 45338 \\ ${ }^{3}$ Department of Agricultural Food and Nutritional Science, University of Alberta, Edmonton, AB, Canada T6G 2P5 \\ ${ }^{4}$ Department of Animal and Food Sciences, University of Kentucky, Lexington 40506
}

\begin{abstract}
The objectives of this study were to investigate how milk replacer (MR) allowance and differing concentrations of starch and neutral detergent fiber in starter alters visceral tissue and overall growth of the calf. Calves were randomly assigned to 1 of 4 dietary treatments (n $=12$ per treatment) arranged in a $2 \times 2$ factorial based on daily MR allowance (MRA) and amount of starch in pelleted starter (SPS) as follows: $0.691 \mathrm{~kg}$ of MR/d [dry matter (DM) basis] with starter containing low or high starch $(12.0 \%$ and $35.6 \%$ starch, respectively) and $1.382 \mathrm{~kg}$ of MR/day (DM) with starter containing low or high starch. All calves were housed in individual pens with straw bedding until wk 5 when bedding was covered to minimize intake. Calves were fed MR twice daily (0700 and $1700 \mathrm{~h}$ ) containing $24.5 \%$ crude protein $(\mathrm{DM})$ and $19.8 \%$ fat $(\mathrm{DM})$, and had access to pelleted starter (increased by $50 \mathrm{~g} / \mathrm{d}$ if there were no refusals before weaning, and then $200 \mathrm{~g} / \mathrm{d}$ during and after weaning) and water starting on d 1. Calves arrived between 1 and $3 \mathrm{~d}$ of age and were enrolled into an 8-wk study, with calves undergoing step-down weaning during wk 7. Intakes were measured daily, and body weight (BW) and blood samples were recorded and collected weekly. Calves were dissected in wk 8 for visceral tissue measurements. Overall, there was increased MR DM intake for the high- $(0.90 \pm 0.01 \mathrm{~kg} / \mathrm{d} ; \pm \mathrm{SE})$ compared with the low-MRA $(0.54 \pm 0.01 \mathrm{~kg} / \mathrm{d})$ calves, whereas starter DM intake increased in low- $(0.47 \pm 0.05 \mathrm{~kg} / \mathrm{d})$ compared with high-MRA $(0.20 \pm 0.05 \mathrm{~kg} / \mathrm{d})$ calves, which was driven by increases in wk 6,7 , and 8 . HighMRA calves had increased BW during wk 2, 3, 4, 5, 6 , and 7 . The difference in BW disappeared by wk 8 ,
\end{abstract}

Received September 13, 2021.

Accepted December 9, 2021.

*Corresponding author: masteele@uoguelph.ca with overall average daily gain having a tendency to be increased in high $(0.57 \pm 0.04 \mathrm{~kg} / \mathrm{d})$ compared with low-MRA $(0.50 \pm 0.04 \mathrm{~kg} / \mathrm{d})$ calves, whereas average daily gain was increased in high-MRA calves during wk 2 and 3 and increased in low-MRA calves during wk 7 and 8 . There were several differences throughout visceral tissue measurements, but most notably, an increase in rumen mass (i.e., full, empty, and digesta weights) in low- compared with high-MRA calves, as well as in low- compared with high-SPS calves was observed. The length, width, and 2-dimensional area of rumen papillae were also increased in low- (area: $0.88 \pm 0.03$ $\left.\mathrm{mm}^{2}\right)$ compared with high-MRA $\left(0.46 \pm 0.03 \mathrm{~mm}^{2}\right)$ calves. The majority of differences were attributed to increased MR allowance, which contributed to reduced pelleted starter intake by more than $50 \%$ and reduced rumen development, whereas differences in starch intake from the completely pelleted starter had minimal effects on overall growth and tissue measurements.

Key words: dairy, calf nutrition, gut development, blood metabolite, weaning

\section{INTRODUCTION}

There has been interest in feeding dairy calves a high amount of milk or milk replacer (MR) during the preweaning period, which has promoted greater rates of weight gain, structural growth, and feed efficiency (Diaz et al., 2001; Khan et al., 2007; Sweeney et al., 2010). However, preweaning calves are usually fed starter to promote dry feed consumption, and starters may contain a wide range of starch content as readily fermentable carbohydrate sources (Hu et al., 2018). Although it is known that increasing the amount of nutrients fed via milk or MR decreases dry feed consumption (de Paula et al., 2017; Mirzaei et al., 2018), the combined effects of MR nutrition and starch content in a starter on calf growth performance through weaning and visceral tissue growth postweaning remains unknown. 
Beyond overall calf growth during the preweaning period, higher amounts of MR have been associated with increased growth of tissues in the lower gut (Geiger et al., 2016; Schäff et al., 2018; Koch et al., 2019). This growth is due to the provision of macronutrients in $\mathrm{MR}$, which also increases basal metabolic requirements (Davis and Drackley, 1998). However, feeding increased MR inversely affects starter intake (Kristensen et al., 2007; Silva et al., 2019), which slows growth of the rumen (Kristensen et al., 2007). Therefore, the appropriate concentrations of $\mathrm{CP}$ and ME need to be balanced in both the MR and starter to promote tissue growth and development throughout the entire gut to support the weaning transition.

Calf starters containing readily fermentable carbohydrates (i.e., starch), which are fermented to produce VFA in the rumen, play a critical role in stimulating rumen epithelial growth (Sakata and Tamate, 1978; Gorka et al., 2009; Malhi et al., 2013). This rumen tissue growth and development is important for the metabolic transition to a true functional ruminant. However, adding too much fermentable carbohydrate may result in ruminal acidosis (Pan et al., 2016), and subsequently a systemic inflammatory response (Khafipour et al., 2009), which may negatively affect growth performance. Suárez et al. (2006a) observed increased ADG in veal calves fed a higher NDF (49.3\% DM basis) compared with a higher starch (59.3\% DM basis) pelleted starter at $12 \mathrm{wk}$, although calves were not weaned in their study and both treatments had the same rumen $\mathrm{pH}$ at $12 \mathrm{wk}$. It should be stated that low ruminal $\mathrm{pH}$ is commonly reported in preweaning dairy calves and thus may not cause the same negative effects seen in adult ruminants (Suárez et al., 2006a; Li et al., 2012; van Niekerk et al., 2021). Also, the inclusion of too much starch, coupled with limited pancreatic amylase production in early life (Toullec and Guilloteau, 1989), may shift fermentation to the lower gut, potentially causing hindgut acidosis and damaging the intestinal epithelium, as described for mature cows (Gressley et al., 2011). Although increasing starch may provide more ME to calves via starter, $\mathrm{Hu}$ et al. (2018) recently demonstrated that based on NRC (2001) calculations, starter ME is only minorly altered (range of 2.85-3.03 Mcal $/ \mathrm{kg}$ of DM), even with starch (and NDF) concentrations ranging from 10 to $50 \%$ of the starter (DM basis). Thus, it is necessary to determine optimal starch concentrations in calf starter to ensure sufficient ME is provided for growth without causing negative effects on health.

Recognizing current industry feeding trends, it is important to investigate how a high amount of MR feeding influences the intake of pelleted starters containing differing concentrations of starch, and, subsequently, its effects on growth performance of dairy calves during both the pre- and postweaning phases. We hypothesized that higher MR-fed calves would have increased growth performance and enhanced visceral tissue growth compared with lower MR-fed calves preweaning, whereas starch concentrations in starter would have no effect on growth performance or growth of visceral tissue (due to similar ME intake). The objectives were to measure the effects of amount of MR fed and level of starch in starter on growth performance, blood metabolites, and visceral tissue growth.

\section{MATERIALS AND METHODS}

\section{Animals, Climate, Experimental Design, and Dietary Treatments}

A total of 48 male Holstein-Friesian calves (4.4 \pm $0.25 \mathrm{~d}$ of age) were obtained from multiple nearby dairy farms and transported to the Nurture Research Center in southwest Ohio for the duration of the 8-wk study between October and December, 2019. Our study was conducted from fall to early winter in 2019 with the following average ambient temperature and calculated average temperature-humidity index (THI; Dikmen and Hansen, 2009), respectively: October $=14.0^{\circ} \mathrm{C}$ and 56.4 , November $=6.8^{\circ} \mathrm{C}$ and 44.8 , and December $=$ $5.2^{\circ} \mathrm{C}$ and 41.5 , where the THI equation is as follows:

$$
\begin{gathered}
\mathrm{THI}=(1.8 \times \mathrm{T}+32)-[(0.55-0.0055 \times \mathrm{RH}) \\
\times(1.8 \times \mathrm{T}-26.8)],
\end{gathered}
$$

where $\mathrm{T}=$ ambient air temperature $\left({ }^{\circ} \mathrm{C}\right)$ and $\mathrm{RH}=$ relative humidity (\%).

The study was performed in compliance with the guidelines set by the Guide for the Care and Use of Agricultural Animals in Research and Teaching (FASS, 2010), and the use of calves and experimental procedures complied with the guidelines of the Canadian Council on Animal Care (2009) and were approved by the University of Guelph Animal Care Committee (protocol \#4272). On arrival, calves were placed in individual pens $(1.2 \mathrm{~m} \times 2.4 \mathrm{~m})$ with a coarse rock, tile-drained base bedded with wheat straw in a barn with curtain sides, natural ventilation, and no added heat. The day after arrival, at approximately $0800 \mathrm{~h}$, initial BW was measured and blood samples were taken via jugular venipuncture in a 10-mL glass tube (ref\# 366430; BD Vacutainer), allowed to clot at room temperature, and centrifuged at $3,000 \times g$ at $20^{\circ} \mathrm{C}$ for $20 \mathrm{~min}$ (VWR International), after which serum was transferred to a new tube and stored at $-20^{\circ} \mathrm{C}$. The samples were 
shipped to the Saskatoon Colostrum Company Ltd. (Saskatoon, Canada) to determine serum IgG concentration by radial immunodiffusion analysis (Chelack et al., 1993) with modifications as described in Chamorro et al. (2014), and used to assess passive transfer of immunity. Upon arrival, serum was collected to measure Brix percentage via refractometry; then the initial Brix percentage, initial BW, and location within barn were used to assign calves to treatments using a Microsoft Excel macro-enabled randomization tool, which balanced assignments by the aforementioned variables. Calves were randomly assigned to 1 of 4 dietary treatments $(\mathrm{n}=12$ per treatment) arranged in a $2 \times 2$ factorial based on daily MR allowance (MRA) and amount of starch in pelleted starter (SPS) as follows: (1) $0.691 \mathrm{~kg}$ of MR DM/d with pelleted starter containing low starch (12.0\% DM basis; LL), (2) $0.691 \mathrm{~kg}$ of MR DM/d with pelleted starter containing high starch (35.6\% DM basis, LH), (3) $1.382 \mathrm{~kg}$ of DM/d with pelleted starter containing low starch (HL), and (4) $1.382 \mathrm{~kg}$ of $\mathrm{DM} / \mathrm{d}$ with pelleted starter containing high starch (HH), which started in the second week after all calves received $0.691 \mathrm{~kg}$ of $\mathrm{DM} / \mathrm{d}$ for the first week. For sample-size determination, a power analysis using a power of $80 \%$, an $\alpha$-level of 0.05 , and a minimum difference in BW gain of $100 \mathrm{~g} / \mathrm{d}$ showed the minimal sample size of 8 calves per treatment. All calves were fed MR containing 24.5\% CP (DM) and 19.8\% fat $(\mathrm{DM})$ at $150 \mathrm{~g}$ of powder/L twice daily (0700 and 1700 h) and had access to pelleted starter (increased by 50 $\mathrm{g} / \mathrm{d}$ if there were no refusals before weaning, and then $200 \mathrm{~g} / \mathrm{d}$ during and after weaning) and water starting on d 1 (day after arrival). On d 35 (1 wk before weaning started), the straw bedding in each pen was covered with a coconut fiber mat that had $1.27 \times 1.27$ cm square openings (coir mat 90; One Clarion), which were cleaned of manure daily to help reduce bedding consumption. Jackets (LifeJacket, Genex) were also put on calves to help mitigate any heat loss. All calves underwent a step-down weaning protocol consisting of only morning MR feeding starting d 42 and ending on d 49; thus, the postweaning experimental period lasted from d 49 to $57,58,59$, or 60 , depending on when calves were dissected for tissue samples.

\section{Measurements, Sampling, and Analytical Procedures}

Intake of MR and starter feed were recorded daily. Body weight, BCS, and hip width were measured weekly, and hip height, heart girth, and mid girth were measured at the beginning of the study (d 1) and at the end of the study (d 56). Hip width and height were completed using a measuring stick, whereas heart and mid girth were measured using a tape measure around their chest just behind their front legs and their midsection halfway between front and back legs, respectively. Scoring for BCS was modified from Wildman et al. (1982), with $1=$ thin and $5=$ obese. Feces were scored daily on a scale of 1 to 5 , with $1=$ firm consistency and 5 = watery feces (modified from Kertz and ChesterJones, 2004). Every other bag of MR and starter feed was sampled and composited for nutrient analyses each week (Table 1; with starter feed ingredients provided in Table 2). Blood samples were taken from all calves via jugular venipuncture on d 1, 14, 28, 35, 42, 49, and 56 between 0800 and $1000 \mathrm{~h}(1-3 \mathrm{~h}$ after the morning feeding) in a 10-mL glass serum tube (ref\# 366430; BD Vacutainer). Blood samples were allowed to clot at room temperature until centrifugation at $3,000 \times g$ at $4^{\circ} \mathrm{C}$ for $20 \mathrm{~min}$ (Marathon 21000R; Fisher Scientific), and serum was collected and subsequently stored at $-20^{\circ} \mathrm{C}$ until further analysis. Photometric analyses of metabolites [i.e., glucose via NADPH formation at 340 $\mathrm{nm}, \mathrm{BHB}$ via NADH formation at $340 \mathrm{~nm}$, and nonesterified fatty acids (NEFA) via formation of purple adduct at $550 \mathrm{~nm}$ ] were performed on the Cobas 6000 series analyzer (Roche) at the University of Guelph Animal Health Laboratory. Composite feed samples were analyzed according to AOAC International (2000) for DM (oven method 930.15), ash (oven method 942.05), CP (Kjeldahl method 988.05), fat (alkaline treatment with Röse-Gottlieb method 932.06 for MR; diethyl ether extraction method 2003.05 for starter), NDF with ash (Van Soest et al., 1991) without sodium sulfite or $\alpha$-amylase, ADF with ash (Robertson and Van Soest, 1981), starch ( $\alpha$-amylase method; Hall, 2009), and sugar (colorimetric method; DuBois et al., 1956).

At the end of the $8 \mathrm{wk}$, calves were killed and dissected to measure sections along the gastrointestinal

Table 1. Nutrient analyses of feeds used in the study

\begin{tabular}{|c|c|c|c|}
\hline \multirow[b]{2}{*}{ Nutrient (\% of DM) } & \multirow{2}{*}{$\begin{array}{l}\text { Milk } \\
\text { replacer }\end{array}$} & \multicolumn{2}{|c|}{ Pelleted starter } \\
\hline & & High starch & Low starch \\
\hline DM (\% of as-fed) & 97.2 & 88.2 & 89.1 \\
\hline $\mathrm{CP}$ & 24.5 & 21.5 & 20.9 \\
\hline Fat & 19.8 & 4.3 & 3.7 \\
\hline $\mathrm{ADF}$ & 0.5 & 7.8 & 26.1 \\
\hline $\mathrm{NDF}$ & 1.0 & 19.7 & 44.7 \\
\hline Ash & 6.7 & 6.6 & 6.7 \\
\hline Sugar & - & 4.7 & 4.1 \\
\hline Starch & - & 35.6 & 12.0 \\
\hline $\mathrm{ME}^{1}$ & 4.8 & 3.2 & 2.9 \\
\hline
\end{tabular}

${ }^{1}$ Both milk replacer and starter ME were calculated using NRC (2001) equations. Milk replacer ME $=(0.057 \times \mathrm{CP} \%+0.092 \times$ fat $\%+$ $0.0395 \times$ lactose $\%) \times 0.93 ;$ starter $\mathrm{ME}=(1.01 \times$ digestible energy $0.45)+0.0046 \times($ ether extract -3$)$. 
Table 2. Pelleted starter ingredients

\begin{tabular}{|c|c|c|}
\hline Ingredient (\% as-fed) & High starch & Low starch \\
\hline Soybean meal & 24.20 & 18.96 \\
\hline Wheat middlings & 25.00 & 25.00 \\
\hline Corn, ground & 40.24 & 0.89 \\
\hline Soybean hulls & 2.00 & 47.05 \\
\hline Molasses & 2.00 & 2.00 \\
\hline Maltodextrin & 2.50 & 2.50 \\
\hline Soybean oil & 1.00 & 1.00 \\
\hline Salt & 0.40 & 0.40 \\
\hline Calcium carbonate & 1.51 & 0.82 \\
\hline Monocalcium phosphate & 0.00 & 0.23 \\
\hline Bovatec $91^{1}$ & 0.03 & 0.03 \\
\hline Ameribond $2 \mathrm{x}^{2}$ & 0.30 & 0.30 \\
\hline Clarifly larvicide $0.67 \%^{3}$ & 0.08 & 0.08 \\
\hline Vitamins, trace minerals & 0.75 & 0.75 \\
\hline
\end{tabular}

${ }^{1}$ Lasalocid $90.7 \mathrm{~g}$ per pound (Zoetis).

${ }^{2}$ Pellet binder (LignoTech USA Inc.).

${ }^{3}$ Diflubenzuron $0.67 \%$ (Wellmark International).

tract (GIT; i.e., abomasum, reticulorumen, duodenum, jejunum, ileum, cecum, and colon) and other visceral organs (i.e., liver, spleen, pancreas, kidneys, gallbladder), and to collect samples from the GIT for histological analysis. Calves were randomly assigned to be dissected on d $57,58,59$, or 60 , with each day balanced by treatment. On the dissection day, each section of the GIT was separated, weighed full, and emptied to obtain tissue and content weight; the previously described visceral tissues were weighed as well. Subsequently, tissue samples (about $2-4 \mathrm{~cm}$ in length) were taken from the rumen (ventral sac), duodenum, proximal jejunum, distal jejunum, ileum, and colon and washed 3 times in $1 \times$ PBS. Samples were stored in $10 \%$ neutral buffered formalin for $48 \mathrm{~h}$ before being switched to $70 \%$ ethanol until processing. Tissues were processed and embedded in paraffin wax before the resultant tissue slides were stained with hematoxylin and eosin for 2-dimensional morphometric measurements of structures. Images were taken in brightfield using a Leica DM750 microscope fitted with a Leica ICC50 W camera (Leica) and subsequently opened and measured using ImageJ analysis software (Schneider et al., 2012). We measured rumen papillae with 50 line measurements for muscularis, submucosa, epithelial (referring to the strata: basale, spinosum, and granulosum), and corneum and keratin layer thickness; we measured intestinal (duodenum, proximal jejunum, distal jejunum, and ileum) villi and crypts with 10 line measurements for villi height and width and crypt depth and width; we measured colon crypts with 10 line measurements for crypt depth and width. For small intestine sections, the villus height: crypt depth (VC) ratio was calculated as well as the mucosal surface area (MSA) index, which uses the mucosal-to-serosal amplification ratio as presented in Kisielinski et al. (2002). The equation is as follows:

$$
\mathrm{M}=\frac{\left[(\mathrm{a} \times \mathrm{b})+\left(\frac{\mathrm{a}}{2}+\frac{\mathrm{c}}{2}\right)^{2}-\left(\frac{\mathrm{a}}{2}\right)^{2}\right]}{\left(\frac{\mathrm{b}}{2}+\frac{\mathrm{c}}{2}\right)^{2}}
$$

where $\mathrm{M}=$ mucosal surface area index, $\mathrm{a}=$ villus width $(\mu \mathrm{m}), \mathrm{b}=$ villus height $(\mu \mathrm{m})$, and $\mathrm{c}=$ crypt width $(\mu \mathrm{m})$. Formalin fixed rumen tissue was used to measure 2-dimensional papillae area using a stereomicroscope (Leica MZ12.5; Leica) with images opened and analyzed in ImageJ, where the height and width of 15 representative papillae were measured per calf.

\section{Statistical Analysis}

Intake, growth, gross tissue measurements, and histology measurements were analyzed using the MIXED procedure of SAS 9.4 (SAS Institute). The study was designed as a complete randomized design with $2 \times$ 2 factorial arrangement of treatments. The model included the fixed effects of MRA and SPS, with the repeated measures data (intake and growth) including week and their interactions. The random effects were origin farm and calf within dietary treatment, and calf was the experimental unit. All analyses included initial serum $\operatorname{IgG}$ as a covariate and the best-fit covariance structures as determined by Akaike information criterion when appropriate. Multiple means comparisons using the PDIFF option with the Tukey adjustment were completed for meaningful interaction differences. Least squares means \pm standard errors of the mean are reported for all variables. Pearson correlation coefficients were generated using PROC CORR in SAS 9.4 to assess the relationship between intake, tissue measurements at dissection, and rumen and lower gut histology measurements. Fecal scores were analyzed using the FREQ procedure of SAS 9.4 to compare the frequency of diarrhea between treatments. Significance was declared when $P \leq 0.05$ and a tendency when 0.10 $\geq P>0.05$.

\section{RESULTS}

\section{Health, Feed Intake, and Growth Performance}

The initial serum IgG results showed that all calves within each treatment were still at or above the "good" category (serum IgG concentration $\geq 18.0 \mathrm{mg} / \mathrm{mL}$ ) suggested by Lombard et al. (2020); however, after treatments were randomly assigned, we observed a difference between low-SPS $(23.6 \pm 1.6 \mathrm{mg} / \mathrm{mL})$ and high-SPS $(28.6 \pm 1.6 \mathrm{mg} / \mathrm{mL})$ calves. Fecal scores were assessed throughout the study with no differences detected per 
treatment for day experiencing diarrhea $(\mathrm{LL}=1.90 \%$, $\mathrm{LH}=1.02 \%, \mathrm{HL}=2.05 \%$, and $\mathrm{HH}=1.17 \%$ ).

There were no effects for the interactions of MRA $\times$ SPS and SPS $\times$ week or the main effect of SPS for MR DMI, starter DMI, total DMI, CP DMI, and ME intake. Treatments were designed to have increased MR DMI for the high-MRA $(0.90 \pm 0.01 \mathrm{~kg} / \mathrm{d})$ compared with the low-MRA $(0.54 \pm 0.01 \mathrm{~kg} / \mathrm{d})$ calves, which is shown in Table 3 and Figure 1A for wk 2, 3, 4, 5, 6, and 7. Conversely, starter DMI was increased in lowMRA $(0.47 \pm 0.05 \mathrm{~kg} / \mathrm{d})$ compared with high-MRA $(0.20 \pm 0.05 \mathrm{~kg} / \mathrm{d})$ calves, as shown in Table 3 and Figure 1B for wk 2, 3, 6, 7, and 8. Total DMI was increased in high-MRA calves during wk 2,3 , and 4 and in low-MRA calves during wk 8 but did not differ for the main effect of MRA. Overall, total $\mathrm{CP}$ intake was increased in high-MRA $(262.42 \pm 10.93 \mathrm{~g} / \mathrm{d})$ compared with low-MRA $(232.57 \pm 10.93 \mathrm{~g} / \mathrm{d})$ calves and was increased in high-MRA calves during wk 2, 3, 4, and 5 , whereas it was increased in low-MRA calves during wk 8 (Figure 1C). Also, overall total ME intake was increased in high-MRA (4.95 $\pm 0.12 \mathrm{Mcal} / \mathrm{d})$ compared with low-MRA $(4.03 \pm 0.12 \mathrm{Mcal} / \mathrm{d})$ calves and was increased in high-MRA calves during wk 2, 3, 4, 5, and 6 (Figure 1D), but increased in low-MRA calves during wk 8. For CP:ME intake (Figure 1E), there was an MRA effect with an increase in low-MRA ( $56.53 \pm 0.20$ $\mathrm{g}$ of $\mathrm{CP} /$ Mcal of ME) compared with high-MRA (53.93 $\pm 0.20 \mathrm{~g}$ of $\mathrm{CP} / \mathrm{Mcal}$ of ME) calves, and an SPS effect with an increase in low-SPS $(56.02 \pm 0.20 \mathrm{~g}$ of $\mathrm{CP} /$ Mcal of ME) compared with high-SPS $(54.44 \pm 0.20 \mathrm{~g}$ $\mathrm{CP} /$ Mcal ME) calves. Also, there was a tendency for the interaction of MRA $\times \mathrm{SPS}(\mathrm{LL}=57.60 \pm 0.60, \mathrm{LH}$ $=55.46 \pm 0.29, \mathrm{HL}=54.44 \pm 0.29$, and $\mathrm{HH}=53.41$ $\pm 0.29 \mathrm{~g}$ of $\mathrm{CP} / \mathrm{Mcal}$ of $\mathrm{ME}$ ), as well as an increase in low-MRA calves during wk 4, 5, 6, and 7 and an increase in low-SPS calves during wk 6,7 , and 8 .

The overall growth of calves was influenced by dietary treatments, with high-MRA calves having increased BW during wk 2, 3, 4, 5, 6, and 7 (Figure 2A), although the difference in BW disappeared by wk 8 (postweaning) and there were no differences for the interactions of MRA $\times$ SPS and SPS $\times$ week and main effect of SPS. The ADG was affected by MRA $\times$ week, with high-MRA calves having increased growth rates during wk 1,2, and 3 and low-MRA calves having increased growth rates during wk 7 and 8 . There were no differences in BW, ADG, measures of feed efficiency (gain: feed or gain:ME intake) or other growth measurements for the interactions of MRA $\times$ SPS, SPS $\times$ week, or main effect of SPS, but calves fed high MRA compared with low-MRA had greater final hip width, final hip height, hip height change, final heart girth, heart girth change, final BCS, and BCS change.

\section{Blood Metabolites and Visceral Tissue Growth}

The metabolites of interest in this study were glucose, BHB, and NEFA, which are shown in Figure 3. There were no effects for the interactions of MRA $\times$ SPS and SPS $\times$ week or the main effect of SPS for glucose, $\mathrm{BHB}$, and NEFA. There was a difference in glucose for the interaction of MRA $\times$ week, with high-MRA calves having increased glucose in wk 4 (Figure 3A), whereas there was also a main effect of increased glucose in highMRA $(5.57 \pm 0.07 \mathrm{mM})$ compared with low-MRA (5.44 $\pm 0.07 \mathrm{mM}$ ) calves. For BHB, there was a difference in the interaction of MRA $\times$ week effect, where BHB increased for low-MRA compared with high-MRA calves in wk 6 and 7 (Figure 3B). Also, for BHB, the main effect of MRA was significantly increased in low-MRA $(103.27 \pm 4.29 \mu M)$ compared with high-MRA (71.44 $\pm 4.30 \mu M)$ calves. For NEFA, there was a difference for MRA $\times$ week with an increase in blood NEFA in wk 8 for high-MRA calves (Figure 3C). The main effect of MRA was increased in high-MRA $(0.21 \pm 0.07 \mathrm{mM})$ compared with low-MRA $(0.19 \pm 0.07 \mathrm{mM})$ calves.

The visceral tissue measurements taken during the wk 8 dissection are presented in Table 4 . The interaction of MRA $\times$ SPS was only significant for spleen weight and its $\%$ of BW, where HL spleen weights were heavier than LL calves, and other treatments were intermediate. Regarding SPS effects, differences were mainly observed in the reticulorumen, with all measures at dissection increased in low-SPS calves compared with high-SPS calves. Moreover, low-SPS calves had increased colon as \% BW, and colon digesta and highSPS calves had increased liver as \% BW. Tendencies for SPS effects included low-SPS calves having increased colon weight, whereas high-SPS calves had increased kidney weight, kidneys as \% BW, and gallbladder as $\%$ BW. There were many more differences in the main effect of MRA compared with SPS, which were all increased in low-MRA compared with high-MRA calves for all reticulorumen measures, full abomasum as \% BW, all duodenum measures except empty weight and length, and the full weight, full weight as $\% \mathrm{BW}$, and digesta of the cecum. There were also tendencies for low-MRA calves to have increased empty weight of jejunum as $\%$ BW and full colon as $\%$ BW.

Tissue structure measurements are reported in Table 5. The 2-dimensional measurements of rumen papillae from the ventral sac showed an increase in length, width, and area in low-MRA compared with high-MRA calves. Rumen epithelial strata thickness was measured as well, with no MRA $\times$ SPS interaction or main effects of MRA or SPS for the muscularis and corneum or keratin layer thickness. As for the submucosal layer thickness, there was an increase in low-SPS (459.81 \pm 
Table 3. Performance of calves fed different amounts of milk replacer (MR) or starch concentrations in starter during the 8-wk study

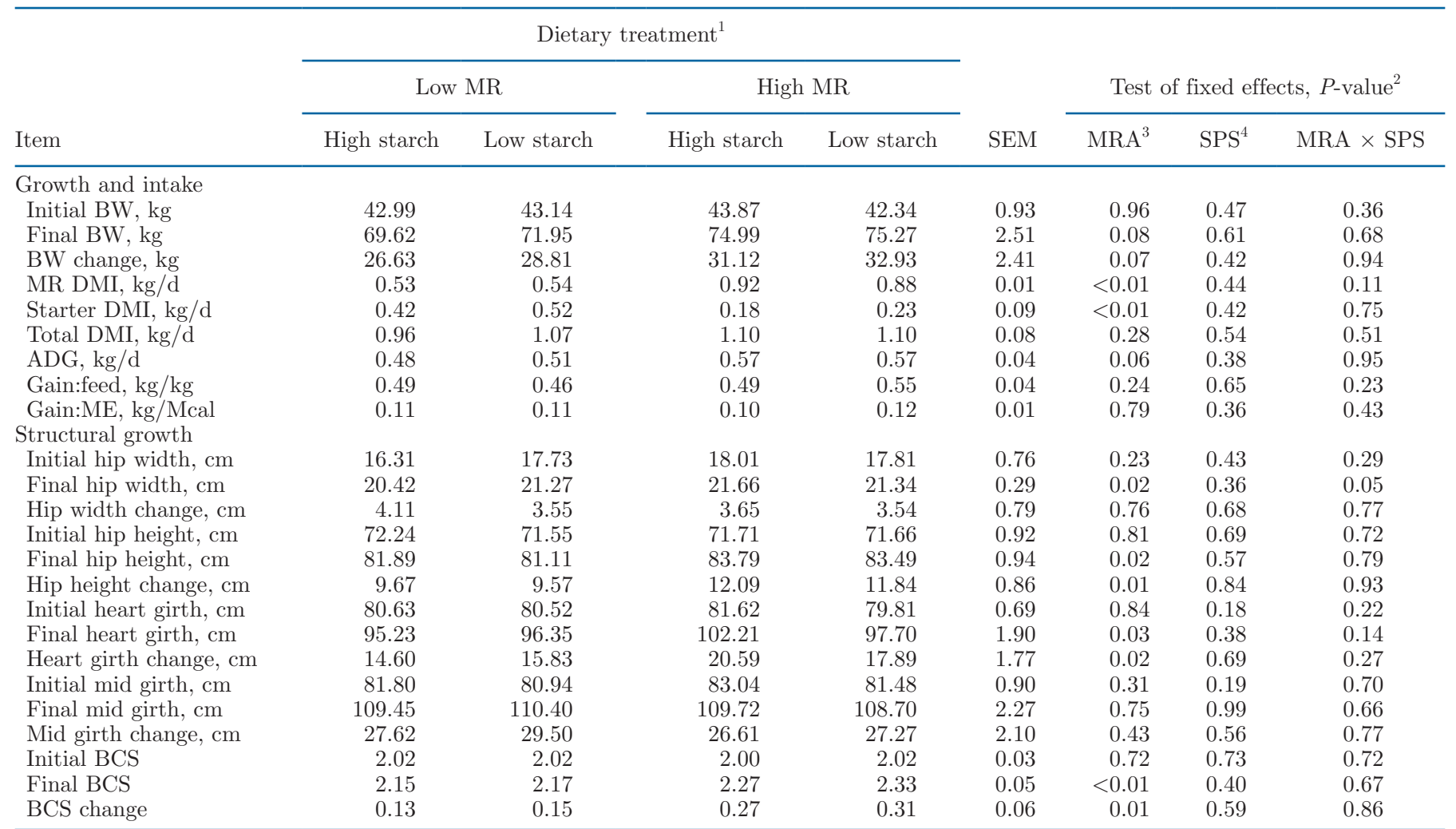

${ }^{1}$ Dietary treatments were as follows: low MR and high starch starter (LH), low MR and low starch starter (LL), high MR and high starch starter $(\mathrm{HH})$, and high MR and low starch starter $(\mathrm{HL}) . \mathrm{LH}=\mathrm{MR}$ fed at $0.691 \mathrm{~kg}$ of DM/d with pelleted starter containing $35.6 \%$ starch (DM basis), $\mathrm{LL}=\mathrm{MR}$ fed at $0.691 \mathrm{~kg}$ of DM/d with pelleted starter containing $12.0 \%$ starch (DM basis), HH $=1.382 \mathrm{~kg}$ of DM/d with pelleted starter containing $35.6 \%$ starch (DM basis), and $\mathrm{HL}=1.382 \mathrm{~kg}$ of DM/d with pelleted starter containing $12.0 \%$ starch (DM basis), which started in the second week after all calves received $0.691 \mathrm{~kg}$ of DM/d for the first week. All calves were fed a MR containing $24.5 \% \mathrm{CP}$ (DM) and $19.8 \%$ fat $(\mathrm{DM})$ at $150 \mathrm{~g} / \mathrm{L}$ twice daily $(0700$ and $1700 \mathrm{~h})$ and had access to pelleted starter (increased by $50 \mathrm{~g} / \mathrm{d}$ if there were no refusals before weaning and then $200 \mathrm{~g} / \mathrm{d}$ during and after weaning) and water starting on $\mathrm{d} 1$.

${ }^{2}$ Significance declared when $P \leq 0.05$ and a tendency declared when $0.05 \leq P \leq 0.10$.

${ }^{3} \mathrm{MRA}=\mathrm{MR}$ allowance.

${ }^{4} \mathrm{SPS}=$ amount of starch in the pelleted starter.

$58.71 \mu \mathrm{m})$ compared with high-SPS $(335.51 \pm 58.71$ $\mu \mathrm{m})$ calves and a tendency for HL to be increased compared with HH calves. The epithelial cell layer tended $(P=0.10)$ to be thicker in high-SPS $(60.97 \pm 3.59 \mu \mathrm{m})$ compared with low-SPS $(55.04 \pm 3.59 \mu \mathrm{m})$ calves, but MRA and interaction of MRA $\times$ SPS had no effect. Intestinal histological measures saw no differences for any measurement for both proximal and distal jejunum, although there were tendencies for deeper crypts in low-MRA calves in the proximal jejunum and wider crypts in low-SPS calves in the distal jejunum. For the duodenum, there was an MRA $\times$ SPS interaction for crypt depth and VC ratio. For crypt depth, the LH calves had deeper crypts than LL calves, whereas LL calves had an increased VC ratio compared with $\mathrm{LH}$ and HL calves. Also, there was an effect of SPS on duodenum crypt depth and a tendency for $\mathrm{VC}$ ratio, with
high-SPS calves having deeper crypts than low-SPS calves and low-SPS calves having a higher $\mathrm{VC}$ ratio compared with high-SPS calves. The ileal villus height and MSA index were affected by SPS, with longer villi in low-SPS compared with high-SPS calves and an increased MSA index in high-SPS compared with lowSPS calves. There was also a tendency for an increased VC ratio in low-SPS compared with high-SPS calves. Also, differences were observed for the effect of MRA in the colon, where crypt width was larger and there was a tendency for deeper crypts in low-MRA compared with high-MRA calves.

\section{Correlation Results}

Pearson correlation coefficients were generated and are presented in Supplemental Tables S1, S2, S3, and 

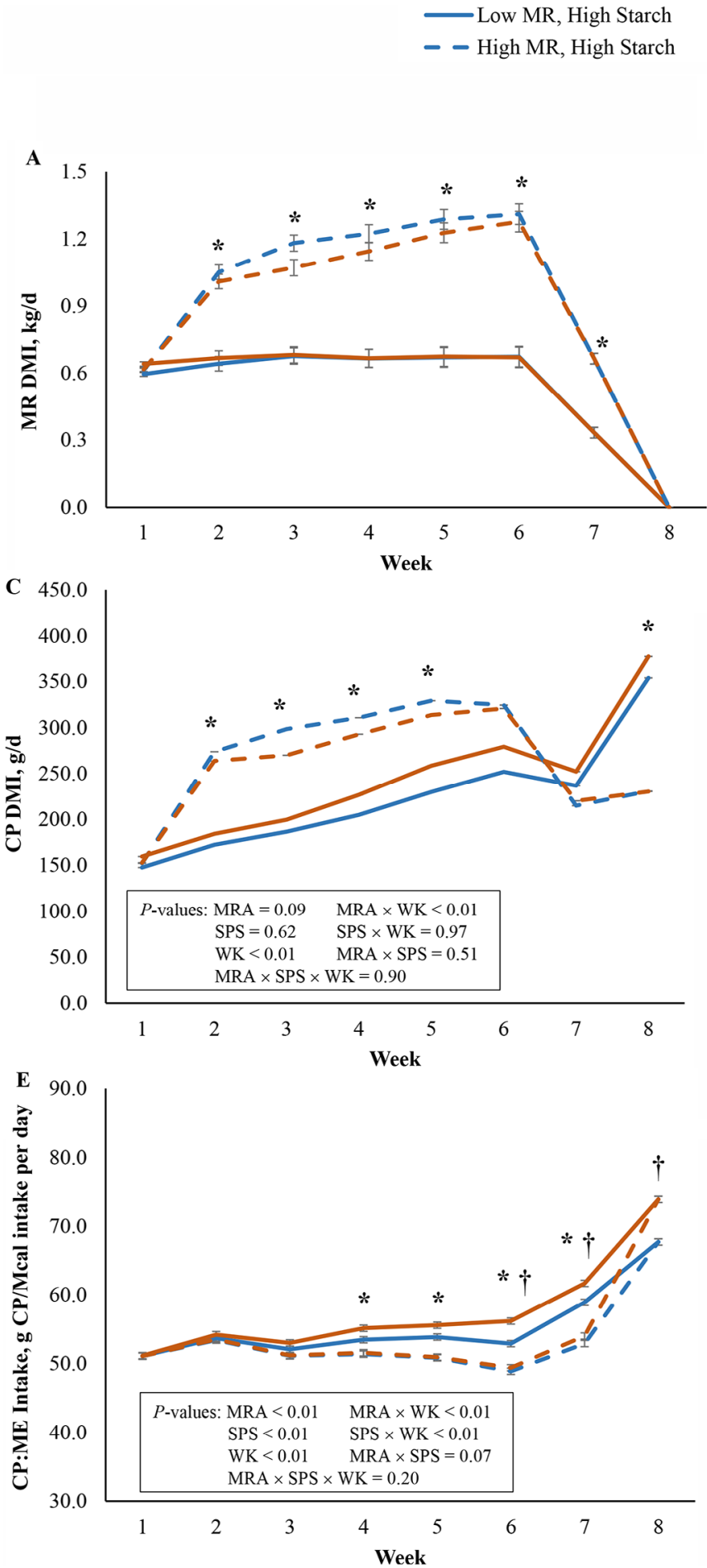
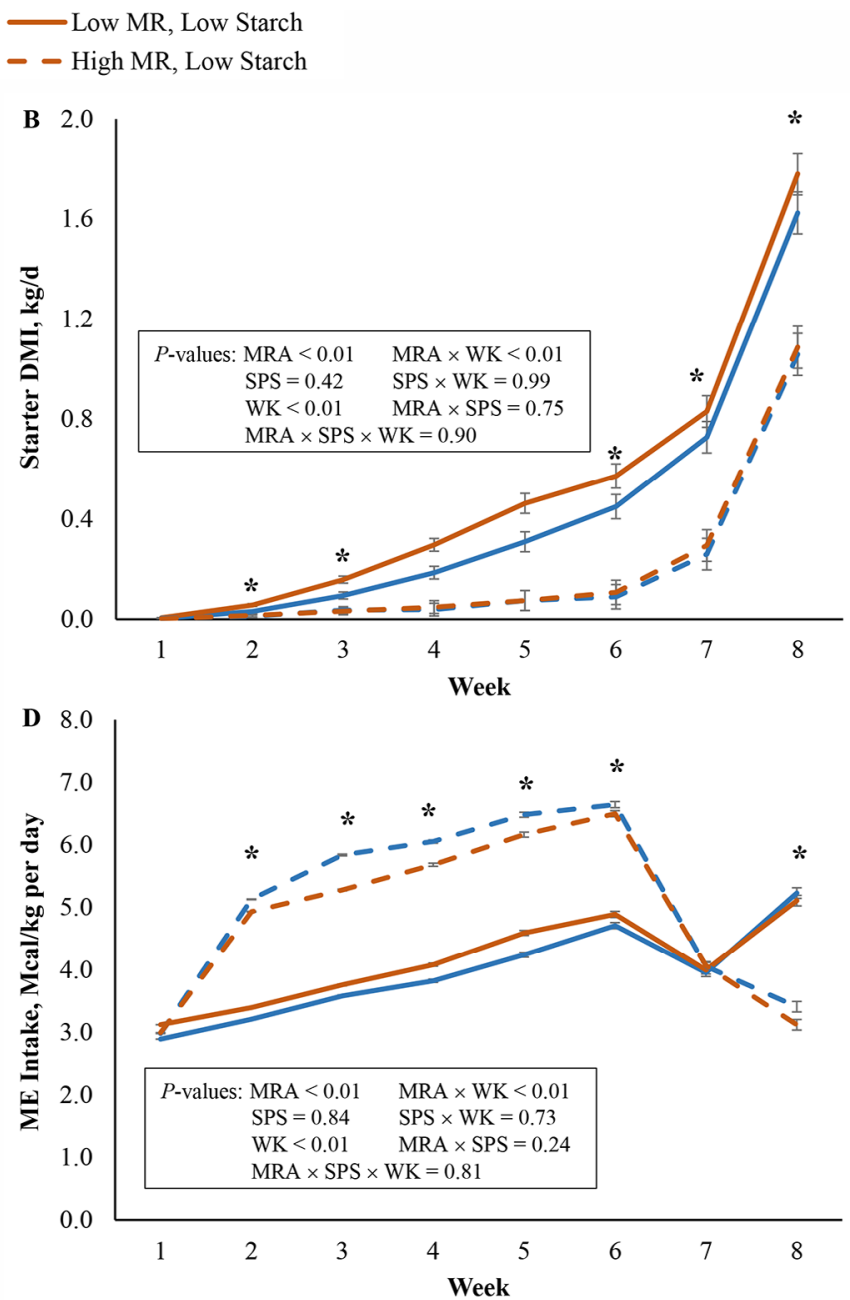

Figure 1. Daily DMI averaged by week for (A) milk replacer (MR), (B) starter, (C) total CP, (D) total ME, and (E) CP:ME. Dietary treatments were as follows: low MR and high starch starter (LH), low MR and low starch starter (LL), high MR and high starch starter (HH), and high MR and low starch starter (HL). LH = MR fed at $0.691 \mathrm{~kg}$ of DM/d with pelleted starter containing $35.6 \%$ starch (DM basis), LL = MR fed at $0.691 \mathrm{~kg}$ of $\mathrm{DM} / \mathrm{d}$ with pelleted starter containing $12.0 \%$ starch (DM basis), $\mathrm{HH}=1.382 \mathrm{~kg}$ of DM/d with pelleted starter containing $35.6 \%$ starch (DM basis), and $\mathrm{HL}=1.382 \mathrm{~kg}$ of DM/d with pelleted starter containing $12.0 \%$ starch (DM basis), which started in the second week after all calves received $0.691 \mathrm{~kg}$ of $\mathrm{DM} / \mathrm{d}$ for the first week. All calves were fed a MR containing $24.5 \% \mathrm{CP}$ (DM) and $19.8 \%$ fat (DM) at $150 \mathrm{~g} / \mathrm{L}$ twice daily $(0700$ and $1700 \mathrm{~h}$ and had access to pelleted starter (increased by $50 \mathrm{~g} / \mathrm{d}$ if there were no refusals before weaning and then $200 \mathrm{~g} / \mathrm{d}$ during and after weaning) and water starting on d $1 . \mathrm{MRA}=\mathrm{MR}$ allowance, SPS $=$ starch amount in pelleted starter, and WK $=$ week. Significance declared when $P \leq 0.05$ and a tendency declared when $0.05 \leq P \leq 0.10$. A significant interaction of MRA $\times$ WK or SPS $\times$ WK are denoted with $*$ or $\dagger$, respectively. Error bars represent SEM. 


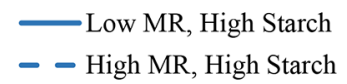

Low MR, Low Starch

- - High MR, Low Starch
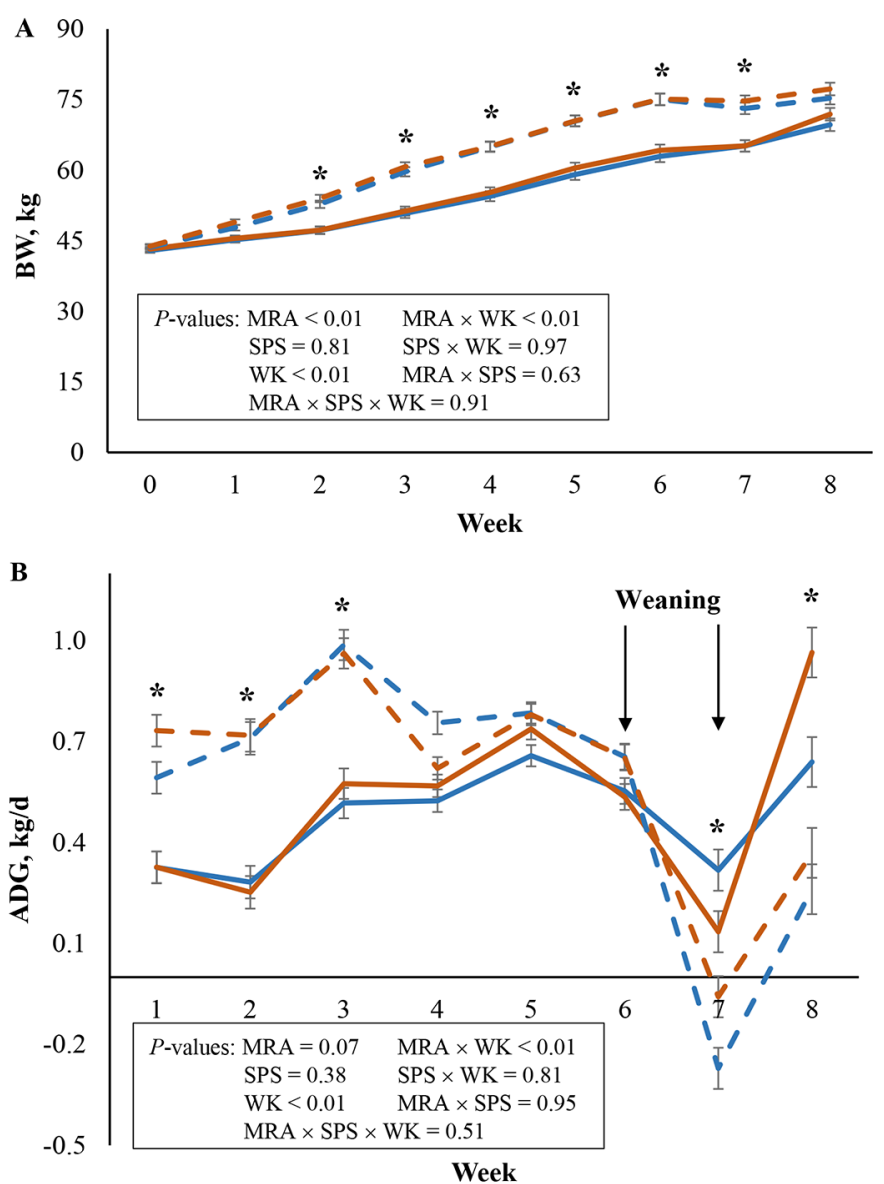

Figure 2. Weekly growth measurements for (A) BW and (B) ADG. Dietary treatments were as follows: low MR and high starch starter (LH), low MR and low starch starter (LL), high MR and high starch starter $(\mathrm{HH})$, and high $\mathrm{MR}$ and low starch starter (HL). $\mathrm{LH}=$ MR fed at $0.691 \mathrm{~kg}$ of DM/d with pelleted starter containing $35.6 \%$ starch (DM basis), LL $=$ MR fed at $0.691 \mathrm{~kg}$ of $\mathrm{DM} / \mathrm{d}$ with pelleted starter containing $12.0 \%$ starch (DM basis), $\mathrm{HH}=1.382 \mathrm{~kg}$ of DM/d with pelleted starter containing $35.6 \%$ starch (DM basis), and HL = $1.382 \mathrm{~kg}$ of DM/d with pelleted starter containing $12.0 \%$ starch (DM basis), which started in the second week after all calves received 0.691 $\mathrm{kg}$ of $\mathrm{DM} / \mathrm{d}$ for the first week. All calves were fed a MR containing $24.5 \% \mathrm{CP}(\mathrm{DM})$ and $19.8 \%$ fat $(\mathrm{DM})$ at $150 \mathrm{~g} / \mathrm{L}$ twice daily $(0700$ and $1700 \mathrm{~h}$ and had access to pelleted starter (increased by $50 \mathrm{~g} / \mathrm{d}$ if there were no refusals before weaning and then $200 \mathrm{~g} / \mathrm{d}$ during and after weaning) and water starting on $\mathrm{d} 1 . \mathrm{MRA}=\mathrm{MR}$ allowance, SPS $=$ starch amount in pelleted starter, and $\mathrm{WK}=$ week. Significance declared when $P \leq 0.05$ and a tendency declared when $0.05 \leq P \leq$ 0.10 . A significant interaction of MRA $\times$ week is denoted with $*$. Error bars represent SEM.

S4 (https://doi.org/10.6084/m9.figshare.19010174.v1). There are many relationships observed, notably weak to strong positive correlations ( $\mathrm{r}$ values from 0.26 to 0.91) between starter intake preweaning and during or postweaning with reticulorumen weight, rumen papillae measurements, and lower gut weights, whereas MR
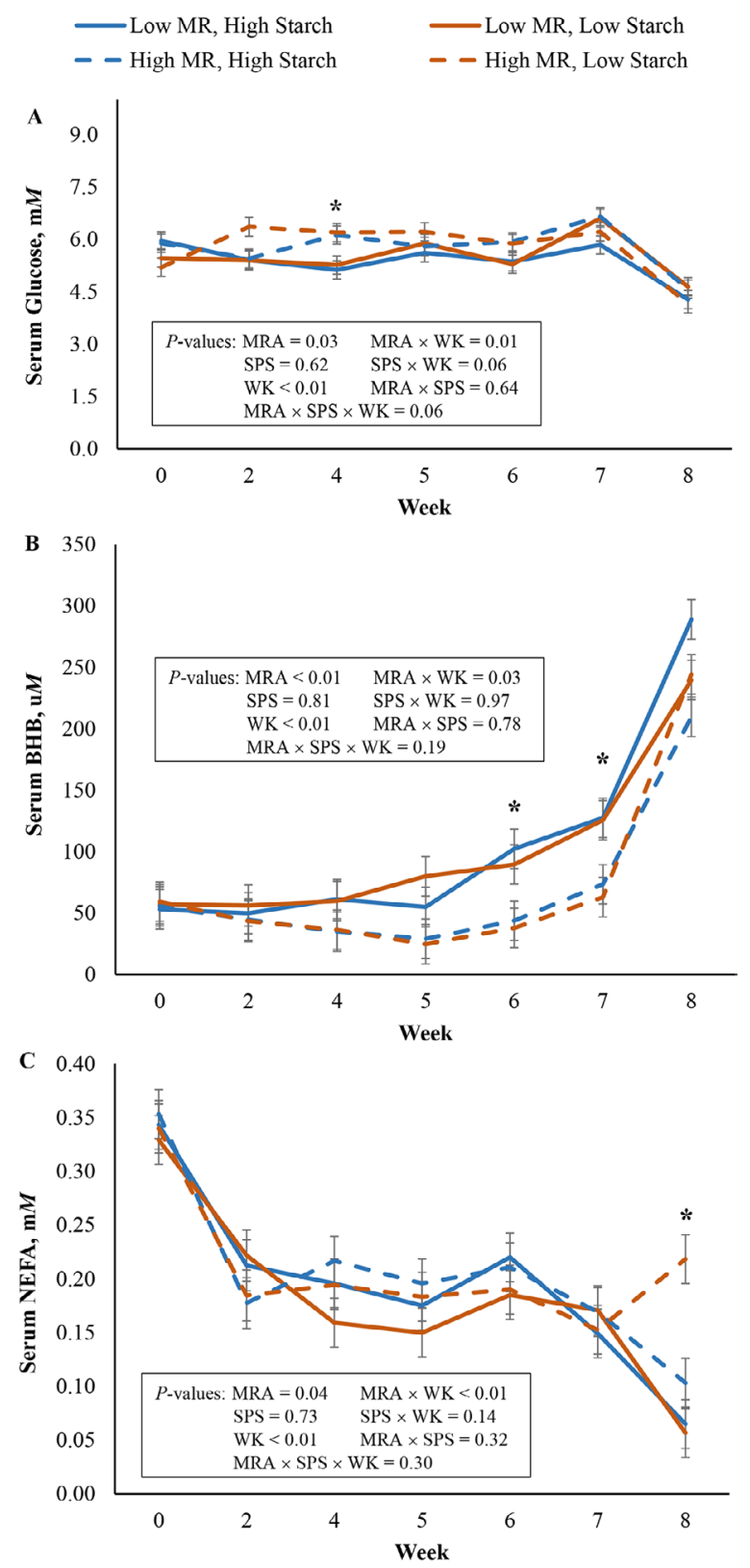

Figure 3. Weekly serum metabolite measurements for (A) glucose, (B) BHB, and (C) nonesterified fatty acids (NEFA). Dietary treatments were as follows: low MR and high starch starter (LH), low MR and low starch starter (LL), high MR and high starch starter (HH), and high MR and low starch starter (HL). LH $=\mathrm{MR}$ fed at $0.691 \mathrm{~kg}$ of DM/d with pelleted starter containing $35.6 \%$ starch (DM basis), LL $=\mathrm{MR}$ fed at $0.691 \mathrm{~kg}$ of DM/d with pelleted starter containing $12.0 \%$ starch (DM basis), $\mathrm{HH}=1.382 \mathrm{~kg}$ of $\mathrm{DM} / \mathrm{d}$ with pelleted starter containing $35.6 \%$ starch (DM basis), and HL $=1.382 \mathrm{~kg}$ of DM/d with pelleted starter containing $12.0 \%$ starch (DM basis), which started in the second week after all calves received $0.691 \mathrm{~kg}$ of $\mathrm{DM} / \mathrm{d}$ for the first week. All calves were fed a MR containing $24.5 \% \mathrm{CP}(\mathrm{DM})$ and $19.8 \%$ fat (DM) at $150 \mathrm{~g} / \mathrm{L}$ twice daily $(0700$ and $1700 \mathrm{~h}$ and had access to pelleted starter (increased by $50 \mathrm{~g} / \mathrm{d}$ if there were no refusals before weaning and then $200 \mathrm{~g} / \mathrm{d}$ during and after weaning) and water starting on d 1. MRA $=$ MR allowance, $\mathrm{SPS}=$ starch amount in pelleted starter, and $\mathrm{WK}=$ week. Significance declared when $P \leq 0.05$ and a tendency declared when $0.05 \leq P \leq 0.10$. A significant interaction of MRA $\times$ WK is denoted with *. Error bars represent SEM. 
Table 4. Visceral tissue measurements at dissection $(8 \mathrm{wk})$ of calves fed different amounts of milk replacer (MR) or starch concentrations in starter

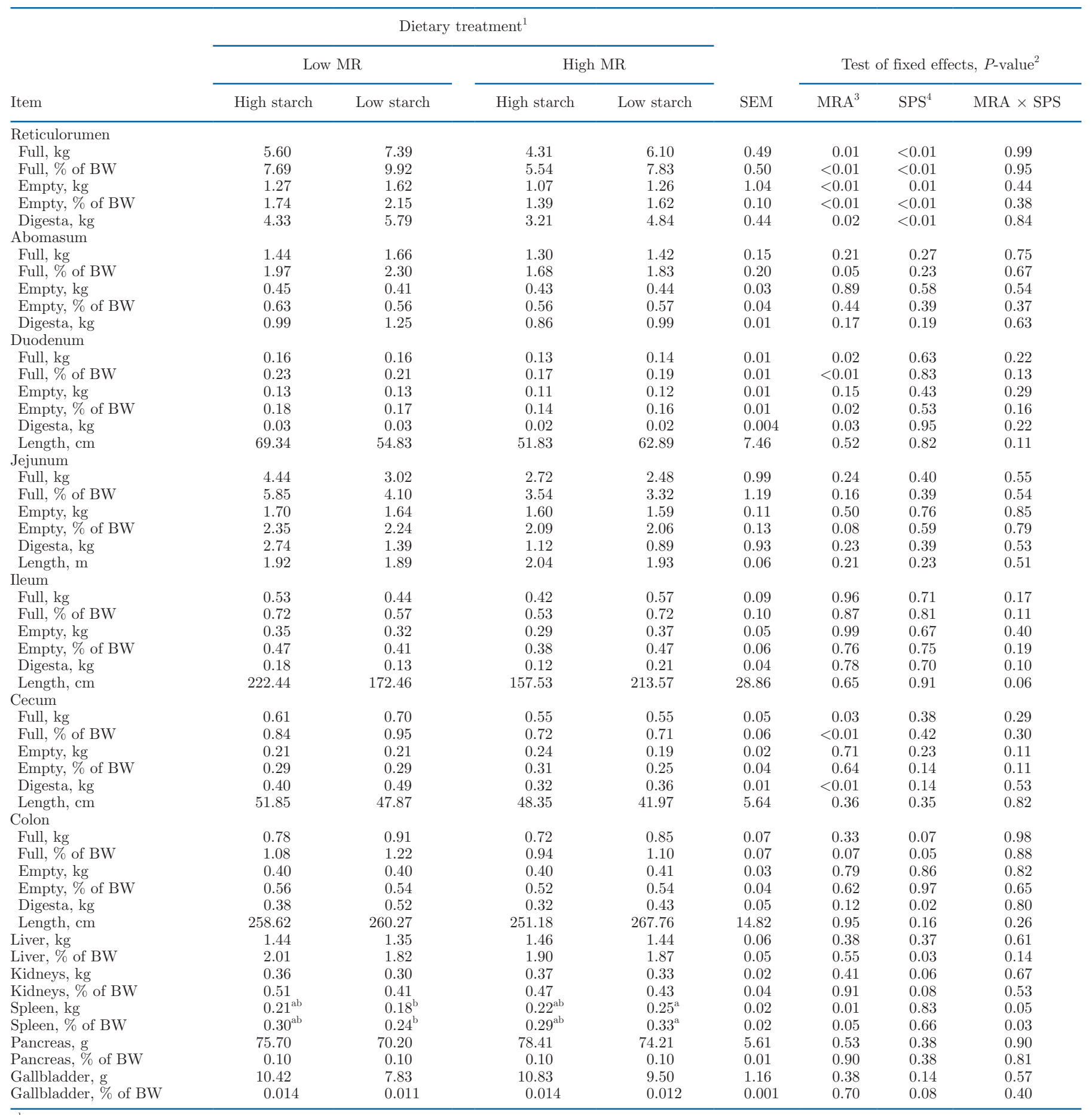

$\overline{\mathrm{a}, \mathrm{b}}$ Superscripts within a row denote significant difference for the interaction.

${ }^{1}$ Dietary treatments were as follows: low MR and high starch starter (LH), low MR and low starch starter (LL), high MR and high starch starter (HH), and high MR and low starch starter (HL). LH = MR fed at $0.691 \mathrm{~kg}$ of DM/d with pelleted starter containing $35.6 \%$ starch (DM basis), LL = MR fed at $0.691 \mathrm{~kg}$ of DM/d with pelleted starter containing $12.0 \%$ starch (DM basis), $\mathrm{HH}=1.382 \mathrm{~kg}$ of DM/d with pelleted starter containing $35.6 \%$ starch (DM basis), and HL $=1.382 \mathrm{~kg}$ of DM/d with pelleted starter containing $12.0 \%$ starch (DM basis), which started in the second week after all calves received $0.691 \mathrm{~kg}$ of DM/d for the first week. All calves were fed a MR containing $24.5 \% \mathrm{CP}(\mathrm{DM})$ and $19.8 \%$ fat (DM) at $150 \mathrm{~g} / \mathrm{L}$ twice daily $(0700$ and $1700 \mathrm{~h})$ and had access to pelleted starter (increased by $50 \mathrm{~g} / \mathrm{d}$ if there were no refusals before weaning and then $200 \mathrm{~g} / \mathrm{d}$ during and after weaning) and water starting on $\mathrm{d} 1$.

${ }^{2}$ Significance declared when $P \leq 0.05$ and a tendency declared when $0.05 \leq P \leq 0.10$.

${ }^{3} \mathrm{MRA}=\mathrm{MR}$ allowance.

${ }^{4} \mathrm{SPS}=$ amount of starch in the pelleted starter. 
intake exhibited negative weak correlations ( $\mathrm{r}$ values from -0.28 to -0.36 ) to reticulorumen weight, rumen papillae 2-dimensional measurements, and some of the same lower gut weights. Other highlights included the following: total CP intake during and postweaning, but not preweaning, was positively correlated with almost all gut tissue weights (full, full as \% BW, empty, and empty as \% BW); total ME intake preweaning, during weaning, and postweaning had either a negative correlation or no relationship with almost all gut tissue weights; total CP, starch, and NDF intake during and after weaning were all positively correlated with rumen papillae measurements; and total ME intake during and after weaning had either a negative correlation or no relationship with rumen papillae 2-dimensional measurements.

\section{DISCUSSION}

The study was designed for high-MRA calves to have increased MR DMI during the preweaning period, whereas the low-MRA calves would have increased starter DMI preweaning leading up to and postweaning. Many studies have shown that higher MR feeding levels are associated with a decrease in starter intake (Quigley et al., 2018; Silva et al., 2019), which was demonstrated in this study. Studies utilizing different weaning strategies (i.e., weaning later or longer weaning process) have shown an improvement in starter intake during and postweaning when calves are fed a higher MR level (Hill et al., 2012; Eckert et al., 2015). Furthermore, previous studies have demonstrated that this increase in MR DMI also led to increased CP and ME intake preweaning (Jaeger et al., 2020a,b), which occurred in this study. The opposite also occurred postweaning when calves fed lower amounts of MR had increased CP and ME intake from starter. However, it should be noted that ME from starter may be overestimated using equations from the NRC (2001) when calves cumulatively consume less than $15 \mathrm{~kg}$ of NFC before weaning (Quigley et al., 2019a,b). Nonetheless, there is an obvious connection between nutrient intake and overall growth, which was demonstrated in this study during the preweaning phase when high-MRA calves had increased $\mathrm{CP}$ and ME intakes and higher BW. By the end of the study, however, the final BW and ADG only tended to be greater in high-MRA calves due to high-MRA weight loss during weaning and increased starter consumption in low-MRA calves, which was also demonstrated by Jaeger et al. (2020b). In our study, the high-MRA calves responded to this drop in nutrient intake by increasing blood NEFA, which mainly stemmed from wk 8 where they had increased levels compared with low-MRA calves. Similarly, this observation is made in transition cows who have increased blood NEFA in response to negative energy balance after calving (reviewed by Bell, 1995). For glucose, there was an overall increase (mainly from wk 4) for high-MRA calves, which may have been due to the higher MR treatment providing more lactose. Interestingly, as discussed in the review by Gerrits (2019) and shown in Bach et al. (2013), even when calves are fed increasing rates of $\mathrm{MR}$, the insulin response typically helps clear glucose effectively to prevent hyperglycemia. In our study, the differences in blood glucose were small and sampled at only 1 postprandial time point. Nevertheless, it is likely that high-MRA calves also had increased insulin responses to help clear glucose quickly enough to minimize differences.

Although blood metabolites help explain how diets are utilized once consumed, focusing on $\mathrm{CP}$ and ME intake is important considering there is a balance that must be met to achieve efficient growth. Although it was a tendency, the LL calves had the highest CP:ME intake throughout the study. This, however, did not translate to any differences in BW or structural growth measurements. Hill et al. (2009a,b) observed that 51 to $55 \mathrm{~g}$ of $\mathrm{CP} / \mathrm{Mcal}$ of $\mathrm{ME}$ was the optimal CP:ME ratio during the preweaning phase (weaned at d 28), whereas Jaeger et al. (2020b) observed that a CP:ME ratio of about 60 $\mathrm{g}$ of $\mathrm{CP} / \mathrm{Mcal}$ of ME was optimal from pre- (weaned at d 42) to postweaning (d 56), suggesting these CP:ME values provided the best conversion to growth based on nutrient input. Comparing these recommendations to our study, it appears that every treatment was within (or almost within) the CP:ME ratio suggested by Hill et al. $(2009 \mathrm{a}, \mathrm{b})$ during the preweaning period. However, compared with Jaeger et al. (2020b), each treatment was below the $60 \mathrm{~g}$ of $\mathrm{CP} / \mathrm{Mcal}$ of $\mathrm{ME}$ throughout the whole study, with the LL treatment being closest and $\mathrm{HH}$ treatment being furthest at $57.60 \pm 0.60$ and 53.41 $\pm 0.29 \mathrm{~g}$ of $\mathrm{CP} / \mathrm{Mcal}$ of ME, respectively. Interestingly, when looking at CP:ME intake from wk 4 to 7 , the low-MRA calves had higher ratios from greater starter intake and less MR intake, as starter provides more protein relative to energy than MR (Table 1). From wk 6 to 8, the low-SPS calves also had higher ratios of CP:ME intake, which was most likely due to the lower starch in the starter, which supplied lower ME (Table 1), and thus lowered ME intake.

Considering growth and intake together, the measures of feed efficiency were not different between treatments, which corroborates the results in the meta-analysis performed by $\mathrm{Hu}$ et al. (2020) that assessed studies using similar MR feeding rates. Although the gain:ME intake was slightly lower in this study $(0.11 \pm 0.01)$ compared 
Table 5. Histology measurements from tissue samples taken at dissection ( $8 \mathrm{wk})$ of calves fed different amounts of milk replacer (MR) or starch concentrations in starter

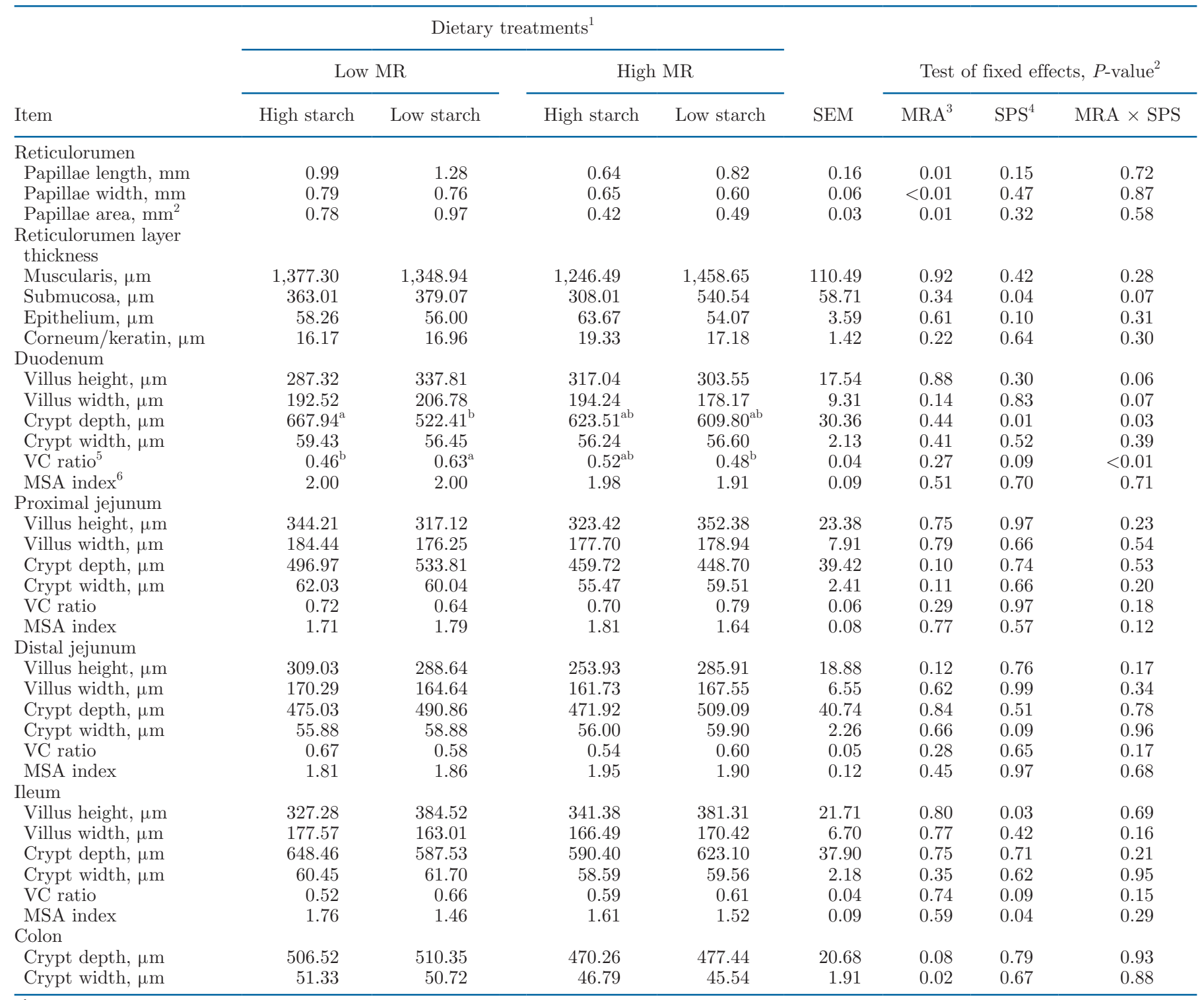

${ }^{\mathrm{a}, \mathrm{b}}$ Superscripts within a row denote significant difference for the interaction.

${ }^{1}$ Dietary treatments were as follows: low MR and high starch starter (LH), low MR and low starch starter (LL), high MR and high starch starter $(\mathrm{HH})$, and high MR and low starch starter (HL). LH $=\mathrm{MR}$ fed at $0.691 \mathrm{~kg}$ of DM/d with pelleted starter containing $35.6 \%$ starch (DM basis), $\mathrm{LL}=\mathrm{MR}$ fed at $0.691 \mathrm{~kg}$ of DM/d with pelleted starter containing $12.0 \%$ starch (DM basis), HH $=1.382 \mathrm{~kg}$ of DM/d with pelleted starter containing $35.6 \%$ starch (DM basis), and $\mathrm{HL}=1.382 \mathrm{~kg}$ of DM/d with pelleted starter containing $12.0 \%$ starch (DM basis), which started in the second week after all calves received $0.691 \mathrm{~kg}$ of $\mathrm{DM} / \mathrm{d}$ for the first week. All calves were fed a MR containing $24.5 \% \mathrm{CP}$ (DM) and $19.8 \%$ fat $(\mathrm{DM})$ at $150 \mathrm{~g} / \mathrm{L}$ twice daily $(0700$ and $1700 \mathrm{~h})$ and had access to pelleted starter (increased by $50 \mathrm{~g} / \mathrm{d}$ if there were no refusals before weaning and then $200 \mathrm{~g} / \mathrm{d}$ during and after weaning) and water starting on $\mathrm{d} 1$.

${ }^{2}$ Significance declared when $P \leq 0.05$ and a tendency declared when $0.05 \leq P \leq 0.10$.

${ }^{3} \mathrm{MRA}=\mathrm{MR}$ allowance.

${ }^{4} \mathrm{SPS}=$ amount of starch in the pelleted starter.

${ }^{5} \mathrm{VC}$ ratio = the villus height:crypt depth ratio calculated from the histological measurements for small intestine sections.

${ }^{6} \mathrm{MSA}$ index $=$ mucosal surface area index as measured from the histological measurements using the equation from Kisielinski et al. (2002).

with $\mathrm{Hu}$ et al. (2020; $0.13 \pm 0.002)$, the gain:feed was similar to that calculated by $\mathrm{Hu}$ et al. $(2020 ; 0.50 \pm$ 0.04 vs. $0.48 \pm 0.01$ ), which showcases the low BW gain obtained in this study. For structural measurements, changes in hip height, heart girth, and BCS were all higher in enhanced MR-fed calves in our study, but 
these significant structural changes were not observed in other studies feeding similar MR levels (Quigley et al., 2018; Dennis et al., 2019).

Although there were some differences in observed intake and growth, it should be noted that the combined factors of calves not consuming their full allotment of MR and low starter intake contributed to reduced overall growth throughout the study, which was much lower than previously observed in studies using similar MR diets. For the low MR intake, this could have been mitigated using 3 feedings throughout the day, but it is also partly explained by the feeding schedule, which had unequal spacing at 14- and 10-h intervals compared with feedings evenly spaced at 12 -h intervals. For the starter intake, in Supplemental Figure S1 (https: //doi.org/10.6084/m9.figshare.19010174.v1) we used a nonlinear equation (22.2 from Table 4 in Quigley et al., 2021) to predict starter DMI to compare with actual DMI for each treatment. From studies using similar MR diets (Klopp et al., 2019; Hu et al., 2020; van Niekerk et al., 2020), we took growth data to calculate ME gap (i.e., ME requirement for a certain ADG - ME intake from MR), which would ultimately help predict the amount of starter DMI required to achieve the desired growth rate. In summary, for each treatment, the actual starter DMI lagged behind predicted starter DMI, which suggested that starter intake was limiting either through insufficient allowance due to protocols or other variables. Klopp et al. (2019) fed slightly lower MR levels (i.e., $660 \mathrm{~g}$ of powder/d for the lower MR group and $820 \mathrm{~g}$ of powder/d and 1,100 $\mathrm{g}$ of powder/d for the higher MR group) and reported starter intakes of 0.60 $\pm 0.04 \mathrm{~kg} / \mathrm{d}$ for their calves fed lower MR and $0.41 \pm$ $0.04 \mathrm{~kg} / \mathrm{d}$ for their calves fed higher MR for the whole 56-d study, both of which are lower than the calculated averages in the meta-analysis conducted by $\mathrm{Hu}$ et al. (2020) and considerably higher than the current study. Furthermore, ADG by lower and higher MR-fed calves in this study are lower than that observed in Klopp et al. $(2019 ; 0.57 \pm 0.03$ and $0.67 \pm 0.03 \mathrm{~kg} / \mathrm{d}$, respectively) and calculated in $\mathrm{Hu}$ et al. (2020; $0.55 \pm 0.01$ and $0.63 \pm 0.01 \mathrm{~kg} / \mathrm{d}$, respectively). Considering MR intake was not lower in the current study, it is clear that starter intake compromised growth.

One clear difference between the current study and others using similar MR diets is the use of completely pelleted starter in the current study compared with texturized starters or a combination of pelleted starter with forage. Dennis et al. (2017) noted a decrease in starter intake between pelleted and texturized starters during the 56 -d nursery period $(0.44 \pm 0.05$ and $0.53 \pm 0.05 \mathrm{~kg} / \mathrm{d}$, respectively), whereas Quigley et al. (2018) noted no difference between intakes of different physical forms of starter, although actual starter intake throughout their study was much higher than what we observed for both lower and higher MR-fed calves (0.75 \pm 0.07 and $0.38 \pm 0.07 \mathrm{~kg} / \mathrm{d}$, respectively). In both of these studies, the low starch was pelleted and high starch was texturized, which makes it difficult to isolate differences based on the physical form of the starter. Straw bedding was also not covered in these studies, which may have also played a role considering forage provision may potentially improve completely pelleted starter intake (reviewed in Suárez-Mena et al., 2016). Contrarily, Terré et al. (2015) observed no difference in starter intake between calves fed only pelleted starter, only texturized starter, and pelleted starter and straw $(0.51 \pm 0.04,0.53 \pm 0.04$, and $0.60 \pm 0.04 \mathrm{~kg} / \mathrm{d}$, respectively). However, rumen $\mathrm{pH}$ was lowest in pelleted only $(5.07 \pm 0.08)$ compared with pelleted and straw (5.32 $\pm 0.08)$ and only texturized fed calves $(5.44 \pm 0.08)$, which further complicates the notion that forage provision supports buffering capacity in the rumen to allow more starter intake. For our study, ruminal $\mathrm{pH}$ was continuously measured before, during, and after weaning using an indwelling $\mathrm{pH}$ probe. Although not reported herein, these $\mathrm{pH}$ results will be presented in another manuscript, and it should be noted that starter intake had no effect on these continuous ruminal $\mathrm{pH}$ measurements and was negatively correlated with mean $\mathrm{pH}$ the week before weaning [i.e., increased starter DMI was negatively correlated with daily mean ruminal $\mathrm{pH} ; \mathrm{T}$. T. Yohe, L. N. Buss, E. J. D. Croft, M. A. Steele (Department of Animal Biosciences, University of Guelph, Guelph, ON, Canada), T. S. Dennis, J. D. Quigley, T. M. Hill, F. X. Suárez-Mena, K. M. Aragona (Nurture Research Center, Provimi, Cargill Animal Nutrition, Lewisburg, OH), A. H. Laarman (Department of Agricultural Food and Nutritional Science, University of Alberta, Edmonton, AB, Canada), J. H. C. Costa (Department of Animal and Food Sciences, University of Kentucky, Lexington), and C. Villot (Lallemand Animal Nutrition, Blagnac, France), unpublished data]. Taken together, these observations showed there was most likely a combination of factors including (but not limited to) the following: availability of bedding, use of a completely pelleted starter, and starter allowance.

Visceral tissue measurements were taken 1 wk after calves were fully weaned, which allowed for the assessment of any potential carryover effects of MR allowance preweaning. For the reticulorumen, there were increases in full, empty, and digesta measurements taken in the low-MRA calves, which was to be expected based on increased starter intake (Yohe et al., 2019). Also, there were increases in every reticulorumen measurement in the low-SPS calves, which was similar to observations 
made by Suárez et al. (2006a,b), where calves fed a higher-NDF pelleted starter $(49.3 \% \mathrm{NDF}$ and $10.8 \%$ starch DM basis) had increased rumen weights at 8 and $12 \mathrm{wk}$ and rumen digesta compared with calves fed a higher-starch pelleted starter $(59.3 \%$ starch and 9.4\% NDF, DM basis), although these calves were not weaned before tissue measurements. These results were further supported by the strong correlations between total NDF intake during or postweaning with full and empty reticulorumen weights $(\mathrm{r}=0.70$ and 0.81 , respectively) compared with starch intake during the same period ( $\mathrm{r}=0.03$ and 0.26 , respectively). Also, the overall increase in blood BHB, as well as the increase in wk 6 and 7, were likely due to higher starter intake that is then fermented in the rumen to VFA, where butyrate is created, absorbed, and metabolized by the rumen epithelium (Quigley, 1996; Suárez et al. 2006b; Connor et al., 2013).

Similar to the reticulorumen measurements, the other differences in visceral tissue measurements were all increased or tended to be increased in LL and $\mathrm{LH}$ compared with HL and HH calves. There is a lack of studies examining visceral tissue growth (other than the forestomach) shortly after weaning, as performed in this study, but Schäff et al. (2018) and Koch et al. (2019) fed calves either a high or low allowance of MR and noted no differences in small intestinal weight or length at d 60 (before weaning), as well as an increase in small intestinal length at d 80 (before weaning), respectively. In our study, although lengths of lower gut segments were not affected by MR allowance, there did seem to be many positive correlations between starter intake both pre-, during, and postweaning and lower gut segment weights. Starter DMI preweaning and empty duodenum weight had an $\mathrm{r}=0.45$, and starter DMI during and postweaning and empty jejunum weight had an $\mathrm{r}=0.59$. In contrast, and in support of the lack of differences observed by Schäff et al. (2018) and Koch et al. (2019), MR intake had essentially no relationship with visceral tissue growth measurements. Interestingly, Górka et al. (2011) fed either whole milk or MR (i.e., higher $\mathrm{CP}$ and $\mathrm{ME}$ provided in whole milk) and observed increased whole small intestine, jejunum, and ileum weights at d 26 (before weaning). In our study, even though high-MRA calves had much higher CP and $\mathrm{ME}$ intakes preweaning, there was a drastic reduction in $\mathrm{CP}$ and $\mathrm{ME}$ intake in the high-MRA calves during the final 2 wk of the study (before dissection and collection of visceral tissues) that was lower than low-MRA calves by wk 8 . This lack of carryover from preweaning to $1 \mathrm{wk}$ postweaning suggests that the gastrointestinal tract has the ability to rapidly adapt to nutrient supply. As such, this 1-wk step-down may have been too abrupt to allow the lower gut to transition smoothly from preweaning.

In the reticulorumen, we observed increased papillae measurements in low MRA-fed calves, which was to be expected based on the importance of starter and concentrate to create VFA that subsequently promotes papillae growth (Sakata and Tamate, 1978; Gorka et al., 2009; Yohe et al., 2019). We also measured cell layer thickness throughout the rumen papillae, with little difference found in the corneum and keratin and muscularis layers, but a thicker epithelial layer and a tendency for a thicker submucosal layer in calves fed higher starch in their starter. Yohe et al. (2019) observed an increase in epithelial layer thickness in calves at 6 wk who consumed starter (27.7\% starch DM) versus calves that only consumed MR, whereas Suárez et al. (2006b) also noted an increase in epithelial thickness in calves fed a high-starch starter versus a high-NDF starter. Contrary to our findings, Yohe et al. (2019) measured increased thickness in submucosal layer thickness in calves fed only MR compared with calves fed MR and starter, but these differences are not easily explained with the present data. Interestingly, even though there were no treatment effects, there were weak negative correlations between corneum and keratin thickness and preweaning starch intake. Concurrently, there was no relationship with starch intake during and postweaning, and there were no correlations between starch intake pre-, during, or postweaning with rumen epithelial thickness.

Further down the GIT, Schäff et al. (2018) and Koch et al. (2019) measured villus height and crypt depth throughout the small intestine after weaning and, similar to our study, observed few differences except for an increase in villi height in the duodenum, proximal jejunum, and ileum in calves fed ad libitum compared with restricted MR. In our study, LL calves had a higher VC ratio in the duodenum compared with LH calves, which was corroborated by the positive relationship between NDF intake during and after weaning and duodenum VC ratio (Supplemental Table S4, https://doi.org/10 .6084/m9.figshare.19010174.v1). Low-SPS calves had increased ileal villi height and a tendency for higher VC ratio compared with high-SPS calves, which are both thought to allow for increased nutrient absorption due to more exposed surface area in the lumen. Interestingly, low-SPS calves had a decreased MSA index, which is used to assess the mucosal surface area utilizing the mucosal-to-serosal amplification ratio (Kisielinski et al., 2002). In our study, the ileum of low-SPS calves had a tendency for higher VC ratio but a lower MSA index, which suggested that assessment of the 3-dimensional structure should also be considered when interpreting histological results. Otherwise, just observing 
an increased villi height, villi width, or $\mathrm{VC}$ ratio may lead one to think absorption capacity is increased when that is only part of the story. Other studies that have measured intestinal MSA index in calves have shown much higher values for every intestinal section $(>4)$ compared with our results, where 2.01 was the highest value for the duodenal MSA index (Fischer-Tlustos et al., 2020; Pyo et al., 2020). Fischer-Tlustos et al. (2020) and Pyo et al. (2020) assessed colostrum management in calves less than $4 \mathrm{~d}$ old, which is much younger than the weaned calves in our study ( $8 \mathrm{wk}$ of age), and they had not consumed solid feed before taking their intestinal samples; however, it should be noted morphological differences do not always equate to absorptive function. The remaining differences were all related to crypt measurements, with the only pattern involving lower MR-fed calves. The LH calves had the longest crypts in the duodenum, whereas low-MRA calves had wider crypts and a tendency for longer crypts in the colon. Crypt depth showed the supply of newly proliferating cells that become the differentiated cells along the villus (Tan and Barker, 2014); based on our results, there may be a connection between increased starter intake and proliferation in the small intestine. Górka et al. (2011) observed a tendency for an increase in mitotic index in the mid jejunum of calves that consumed more starter. The lack of differences aside, there is a dearth of information on lower gut tissue growth and development in calves, especially postweaning, which is an area future research should focus on to help better understand how to prepare calves for this altered metabolism postweaning.

An important aspect of this study was how calves in separate treatments would perform on a 1 wk stepdown weaning protocol from d 42 to d 49. It is clear that the high-MRA calves struggled with this weaning protocol, given their ADG before weaning was approximately $700 \mathrm{~g} / \mathrm{d}$ but dropped to $0 \mathrm{~g} / \mathrm{d}$ or less during and after weaning. Khan et al. (2007) and Silper et al. (2014) demonstrated that utilizing a gradual weaning protocol helps maintain higher growth rates from pre- to postweaning, which is supported by increased starter intake during and postweaning when calves are weaned later or undergo a longer weaning process (Hill et al., 2012; Eckert et al., 2015). Klopp et al. (2019) fed similar MR levels to our study, but either weaned calves "abruptly," which was the same as our 1 wk stepdown from d 42 to 49 , or "gradually," which consisted of 2 reductions in MR starting on d 28 and ending on d 49. They reported higher ADG for their lower and higher MR-fed calves $(0.57 \pm 0.03$ and $0.65 \pm 0.03$ $\mathrm{kg} / \mathrm{d}$, respectively) compared with our study. Interestingly, Klopp et al. (2019) did not see a drastic reduction in ADG in their 1-wk step-down weaned calves, which may have been due to differences in slightly higher total DMI in both lower and higher MR-fed calves (1.18 \pm 0.04 and $1.21 \pm 0.04 \mathrm{~kg} / \mathrm{d}$, respectively in their study). Due to their low starter intake, a gradual weaning protocol may have benefited the high-MRA calves in our study, which further supports the need to investigate step-down weaning protocols when feeding differing MR levels.

\section{CONCLUSIONS}

The results from this study indicated that the amount of MR fed, and consequently starter intake, affected overall, visceral tissue, and ruminal papillae growth. High MR feeding rates improved growth measurements by wk 8 (i.e., BW, hip height, heart girth, and BCS) compared with the low MR feeding rate but reduced starter DMI by more than $50 \%$, which reduced rumen development. Starter DMI was approximately $60 \%$ of expected, which makes interpreting and comparing results challenging. The increase in starter DMI from calves fed a lower amount of MR led to improved ADG around weaning and helped promote growth of visceral tissues, which may help the calf transition from nonruminant to ruminant metabolism.

\section{ACKNOWLEDGMENTS}

The authors thank the staff at the Provimi Nurture Research Center for daily care and husbandry of calves as well as everyone who helped from Michael Steele's, Joao Costa's, and Anne Laarman's laboratories during the dissection procedures. The authors thank the following funding agencies for the financial support provided for this study: Provimi North America, a division of Cargill Animal Nutrition (Brookville, OH), Mitacs (Toronto, Canada), Natural Sciences and Engineering Research Council of Canada (Ottawa, Canada), Alberta Milk (Edmonton, AB, Canada), Westgen (Abbotsford, Canada), BC Dairy Association (Burnaby, Canada), SaskMilk (Regina, Canada), and the Dairy Farmers of Manitoba (Winnipeg, Canada). The authors also thank the staff at the Comparative Pathology and Mouse Phenotyping Shared Resource at Ohio State University (Columbus, $\mathrm{OH}$ ) who are supported in part by National Cancer Institute grant P30CA016058 and helped process histology samples before analysis. The authors have not stated any conflicts of interest.

\section{REFERENCES}

AOAC International. 2000. Official Methods of Analysis. Vol. I. 17th ed. AOAC Int.

Bach, A., L. Domingo, C. Montoro, and M. Terré. 2013. Short communication: Insulin responsiveness is affected by the level of milk 
replacer offered to young calves. J. Dairy Sci. 96:4634-4637. https: //doi.org/10.3168/jds.2012-6196.

Bell, A. W. 1995. Regulation of organic nutrient metabolism during transition from late pregnancy to early lactation. J. Anim. Sci. 73:2804-2819. https://doi.org/10.2527/1995.7392804x.

Canadian Council on Animal Care. 2009. Guidelines on: The Care and Use of Farm Animals in Research, Teaching and Testing. Canadian Council on Animal Care.

Chamorro, M. F., P. H. Walz, D. M. Haines, T. Passler, T. Earleywine, R. A. Palomares, K. P. Riddell, P. Galik, Y. Zhang, and M. D. Givens. 2014. Comparison of levels and duration of detection of antibodies to bovine viral diarrhea virus 1 , bovine viral diarrhea virus 2 , bovine respiratory syncytial virus, bovine herpesvirus 1 , and bovine parainfluenza virus 3 in calves fed maternal colostrum or a colostrum-replacement product. Can. J. Vet. Res. 78:81-88.

Chelack, B. J., P. S. Morley, and D. M. Haines. 1993. Evaluation of methods for dehydration of bovine colostrum for total replacement of normal colostrum in calves. Can. Vet. J. 34:407-412.

Connor, E. E., R. L. Baldwin, C. J. Li, R. W. Li, and H. Chung. 2013. Gene expression in bovine rumen epithelium during weaning identifies molecular regulators of rumen development and growth. Funct. Integr. Genomics 13:133-142. https://doi.org/10.1007/ s10142-012-0308-x.

Davis, C. L., and J. K. Drackley. 1998. The Development, Nutrition, and Management of the Young Calf. 1st ed. Iowa State University Press.

de Paula, M. R., C. E. Oltramari, J. T. Silva, M. P. C. Gallo, G. B. Mourão, and C. M. M. Bittar. 2017. Intensive liquid feeding of dairy calves with a medium crude protein milk replacer: Effects on performance, rumen, and blood parameters. J. Dairy Sci. 100:4448-4456. https://doi.org/10.3168/jds.2016-10859.

Dennis, T. S., F. X. Suarez-Mena, T. M. Hill, J. D. Quigley, and R. L. Schlotterbeck. 2017. Effects of egg yolk inclusion, milk replacer feeding rate, and low-starch (pelleted) or high-starch (texturized) starter on Holstein calf performance through 4 months of age. J. Dairy Sci. 100:8995-9006. https://doi.org/10.3168/jds.2017-13169.

Dennis, T. S., F. X. Suarez-Mena, W. Hu, T. M. Hill, J. D. Quigley, and R. L. Schlotterbeck. 2019. Effects of milk replacer feeding rate and long-term antibiotic inclusion in milk replacer on performance and nutrient digestibility of Holstein dairy calves up to 4 months of age. J. Dairy Sci. 102:2094-2102. https://doi.org/10.3168/jds .2018-15652

Diaz, M. C., M. E. Van Amburgh, J. M. Smith, J. M. Kelsey, and E. L. Hutten. 2001. Composition of growth of Holstein calves fed milk replacer from birth to 105-kilogram body weight. J. Dairy Sci. 84:830-842. https://doi.org/10.3168/jds.S0022-0302(01)74541-9.

Dikmen, S., and P. J. Hansen. 2009. Is the temperature-humidity index the best indicator of heat stress in lactating dairy cows in a subtropical environment? J. Dairy Sci. 92:109-116. https://doi .org/10.3168/jds.2008-1370

DuBois, M., K. A. Gilles, J. K. Hamilton, P. A. Rebers, and F. Smith. 1956. Colorimetric method for determination of sugars and related substances. Anal. Chem. 28:350-356. https://doi.org/10.1021/ ac60111a017.

Eckert, E., H. E. Brown, K. E. Leslie, T. J. DeVries, and M. A. Steele. 2015. Weaning age affects growth, feed intake, gastrointestinal development, and behavior in Holstein calves fed an elevated plane of nutrition during the preweaning stage. J. Dairy Sci. 98:6315-6326. https://doi.org/10.3168/jds.2014-9062.

FASS. 2010. Guide for the Care and Use of Agricultural Animals in Agricultural Research and Teaching. 3rd ed. FASS Inc.

Fischer-Tlustos, A. J., J. Pyo, Y. Song, D. L. Renaud, L. L. Guan, and M. A. Steele. 2020. Short communication: Effect of delaying the first colostrum feeding on small intestinal histomorphology and serum insulin-like growth factor-1 concentrations in neonatal male Holstein calves. J. Dairy Sci. 103:12109-12116. https://doi.org/10 $.3168 /$ jds.2020-18966.

Geiger, A. J., C. L. M. Parsons, R. E. James, and R. M. Akers. 2016. Growth, intake, and health of Holstein heifer calves fed an enhanced preweaning diet with or without postweaning exogenous estrogen. J. Dairy Sci. 99:3995-4004. https://doi.org/10.3168/jds 2015-10405.

Gerrits, W. J. J. 2019. Symposium review: Macronutrient metabolism in the growing calf. J. Dairy Sci. 102:3684-3691. https://doi.org/ $10.3168 /$ jds.2018-15261.

Górka, P., Z. M. Kowalski, P. Pietrzak, A. Kotunia, W. Jagusiak, and R. Zabielski. 2011. Is rumen development in newborn calves affected by different liquid feeds and small intestine development? J. Dairy Sci. 94:3002-3013. https://doi.org/10.3168/jds.2010-3499.

Gorka, P., Z. M. Kowalski, P. Pietrzak, A. Kotunia, R. Kiljanczyk, J. Flaga, J. J. Holst, P. Guilloteau, and R. Zabielski. 2009. Effect of sodium butyrate supplementation in milk replacer and starter diet on rumen development in calves. J. Physiol. Pharmacol. 60(Suppl. $3): 47-53$.

Gressley, T. F., M. B. Hall, and L. E. Armentano. 2011. Ruminant Nutrition Symposium: Productivity, digestion, and health responses to hindgut acidosis in ruminants. J. Anim. Sci. 89:1120-1130. https://doi.org/10.2527/jas.2010-3460.

Hall, M. B. 2009. Analysis of starch, including maltooligosaccharides, in animal feeds: A comparison of methods and a method recommended for AOAC collaborative study. J. AOAC Int. 92:42-49. https://doi.org/10.1093/jaoac/92.1.42.

Hill, T. M., H. G. Bateman II, J. M. Aldrich, and R. L. Schlotterbeck. 2009a. Effects of fat concentration of a high protein milk replacer on calf performance. J. Dairy Sci. 92:5147-5153. https://doi.org/ $10.3168 /$ jds.2009-2245.

Hill, T. M., H. G. Bateman II, J. M. Aldrich, and R. L. Schlotterbeck. 2009b. Optimizing nutrient ratios in milk replacers for calves less than five weeks of age. J. Dairy Sci. 92:3281-3291. https://doi.org/ $10.3168 /$ jds. $2008-1750$

Hill, T. M., H. G. Bateman II, J. M. Aldrich, and R. L. Schlotterbeck. 2012. Methods of reducing milk replacer to prepare dairy calves for weaning when large amounts of milk replacer have been fed. Prof. Anim. Sci. 28:332-337. https://doi.org/10.15232/S1080 -7446(15)30364-8.

Hu, W., T. M. Hill, T. S. Dennis, F. X. Suarez-Mena, K. M. Aragona, J. D. Quigley, and R. L. Schlotterbeck. 2020. Effects of milk replacer feeding rates on growth performance of Holstein dairy calves to 4 months of age, evaluated via a meta-analytical approach. J. Dairy Sci. 103:2217-2232. https://doi.org/10.3168/jds.2019-17206.

Hu, W., T. M. Hill, T. S. Dennis, F. X. Suarez-Mena, J. D. Quigley, J. R. Knapp, and R. L. Schlotterbeck. 2018. Relationships between starch concentration of dry feed, diet digestibility, and growth of dairy calves up to 16 weeks of age. J. Dairy Sci. 101:7073-7081. https://doi.org/10.3168/jds.2018-14583.

Jaeger, B. M., D. Ziegler, D. Schimek, B. Ziegler, H. Chester-Jones, and D. P. Casper. 2020b. Dairy calf growth performance when fed a modified accelerated milk replacer program. Appl. Anim. Sci. 36:352-366. https://doi.org/10.15232/aas.2019-01878.

Jaeger, B. M., D. Ziegler, D. Schimek, B. Ziegler, M. Raeth, H. Chester-Jones, and D. P. Casper. 2020a. Growth performance of newborn dairy calves fed a milk replacer with 2 protein concentrations at 2 feeding rates. Appl. Anim. Sci. 36:48-56. https://doi.org/10 .15232 /aas.2019-01866.

Kertz, A. F., and H. Chester-Jones. 2004. Invited review: Guidelines for measuring and reporting calf and heifer experimental data. J. Dairy Sci. 87:3577-3580. https://doi.org/10.3168/jds.S0022 $-0302(04) 73495-5$.

Khafipour, E., D. O. Krause, and J. C. Plaizier. 2009. A grain-based subacute ruminal acidosis challenge causes translocation of lipopolysaccharide and triggers inflammation. J. Dairy Sci. 92:10601070. https://doi.org/10.3168/jds.2008-1389.

Khan, M. A., H. J. Lee, W. S. Lee, H. S. Kim, S. B. Kim, K. S. Ki, J. K. Ha, H. G. Lee, and Y. J. Choi. 2007. Pre- and postweaning performance of Holstein female calves fed milk through step-down and conventional methods. J. Dairy Sci. 90:876-885. https://doi .org/10.3168/jds.S0022-0302(07)71571-0.

Kisielinski, K., S. Willis, A. Prescher, B. Klosterhalfen, and V. Schumpelick. 2002. A simple new method to calculate small intes- 
tine absorptive surface area in the rat. Clin. Exp. Med. 2:131-135. https://doi.org/10.1007/s102380200018.

Klopp, R. N., F. X. Suarez-Mena, T. S. Dennis, T. M. Hill, R. L. Schlotterbeck, and G. J. Lascano. 2019. Effects of feeding different amounts of milk replacer on growth performance and nutrient digestibility in Holstein calves to 2 months of age using different weaning strategies. J. Dairy Sci. 102:11040-11050. https://doi .org/10.3168/jds.2019-17153.

Koch, C., C. Gerbert, D. Frieten, G. Dusel, K. Eder, R. Zitnan, and H. M. Hammon. 2019. Effects of ad libitum milk replacer feeding and butyrate supplementation on the epithelial growth and development of the gastrointestinal tract in Holstein calves. J. Dairy Sci. 102:8513-8526. https://doi.org/10.3168/jds.2019-16328.

Kristensen, N. B., J. Sehested, S. K. Jensen, and M. Vestergaard. 2007. Effect of milk allowance on concentrate intake, ruminal environment, and ruminal development in milk-fed Holstein calves. J. Dairy Sci. 90:4346-4355. https://doi.org/10.3168/jds.2006-885.

Li, R. W., E. E. Connor, C. Li, R. L. Baldwin VI, and M. E. Sparks. 2012. Characterization of the rumen microbiota of pre-ruminant calves using metagenomic tools. Environ. Microbiol. 14:129-139. https://doi.org/10.1111/j.1462-2920.2011.02543.x.

Lombard, J., N. Urie, F. Garry, S. Godden, J. Quigley, T. Earleywine, S. McGuirk, D. Moore, M. Branan, M. Chamorro, G. Smith, C. Shivley, D. Catherman, D. Haines, A. J. Heinrichs, R. James, J. Maas, and K. Sterner. 2020. Consensus recommendations on calf- and herd-level passive immunity in dairy calves in the United States. J. Dairy Sci. 103:7611-7624. https://doi.org/10.3168/jds .2019-17955.

Malhi, M., H. Gui, L. Yao, J. R. Aschenbach, G. Gabel, and Z. Shen. 2013. Increased papillae growth and enhanced short-chain fatty acid absorption in the rumen of goats are associated with transient increases in cyclin d1 expression after ruminal butyrate infusion. J. Dairy Sci. 96:7603-7616. https://doi.org/10.3168/jds.2013-6700.

Mirzaei, M., N. Dadkhah, B. Baghbanzadeh-Nobari, A. Agha-Tehrani, M. Eshraghi, M. Imani, R. Shiasi-Sardoabi, and M. H. Ghaffari. 2018. Effects of preweaning total plane of milk intake and weaning age on intake, growth performance, and blood metabolites of dairy calves. J. Dairy Sci. 101:4212-4220. https://doi.org/10.3168/jds .2017-13766

NRC. 2001. Nutrient Requirements of Dairy Cattle. 7th ed. National Academies Press

Pan, X. H., L. Yang, F. G. Xue, H. R. Xin, L. S. Jiang, B. H. Xiong, and Y. Beckers. 2016. Relationship between thiamine and subacute ruminal acidosis induced by a high-grain diet in dairy cows. J. Dairy Sci. 99:8790-8801. https://doi.org/10.3168/jds.2016-10865.

Pyo, J., K. Hare, S. Pletts, Y. Inabu, D. Haines, T. Sugino, L. L. Guan, and M. A. Steele. 2020. Feeding colostrum or a 1:1 colostrum:milk mixture for 3 days postnatal increases small intestinal development and minimally influences plasma glucagon-like peptide- 2 and serum insulin-like growth factor-1 concentrations in Holstein bull calves. J. Dairy Sci. 103:4236-4251. https://doi.org/10.3168/jds 2019-17219.

Quigley, J. D. III. 1996. Influence of weaning method on growth, intake, and selected blood metabolites in Jersey calves. J. Dairy Sci. 79:2255-2260. https://doi.org/10.3168/jds.S0022-0302(96)76602 -X.

Quigley, J. D., T. S. Dennis, F. X. Suarez-Mena, C. E. Chapman, T. M. Hill, and K. M. Aragona. 2021. Models to predict dry feed intake in Holstein calves to 4 months of age. J. Dairy Sci. 104:55395556. https://doi.org/10.3168/jds.2020-19581.

Quigley, J. D., T. M. Hill, T. S. Dennis, F. X. Suarez-Mena, and R. L. Schlotterbeck. 2018. Effects of feeding milk replacer at 2 rates with pelleted, low-starch or texturized, high-starch starters on calf performance and digestion. J. Dairy Sci. 101:5937-5948. https:// doi.org/10.3168/jds.2017-13851.

Quigley, J. D., W. Hu, J. R. Knapp, T. S. Dennis, F. X. Suarez-Mena, and T. M. Hill. 2019a. Estimates of calf starter energy affected by consumption of nutrients. 1. Evaluation of models to predict changing digestion on energy content in calf starters. J. Dairy Sci. 102:2232-2241. https://doi.org/10.3168/jds.2018-15353.
Quigley, J. D., W. Hu, J. R. Knapp, T. S. Dennis, F. X. Suarez-Mena, and T. M. Hill. 2019b. Estimates of calf starter energy affected by consumption of nutrients. 2. Effect of changing digestion on energy content in calf starters. J. Dairy Sci. 102:2242-2253. https://doi .org/10.3168/jds.2018-15354.

Robertson, J. B., and P. J. Van Soest. 1981. The Detergent System of Analysis and Its Application to Human Foods. Cornell University. Sakata, T., and H. Tamate. 1978. Rumen epithelial cell proliferation accelerated by rapid increase in intraruminal butyrate. J. Dairy Sci. 61:1109-1113. https://doi.org/10.3168/jds.S0022 -0302(78)83694-7.

Schäff, C. T., J. Gruse, J. Maciej, R. Pfuhl, R. Zitnan, M. Rajsky, and H. M. Hammon. 2018. Effects of feeding unlimited amounts of milk replacer for the first 5 weeks of age on rumen and small intestinal growth and development in dairy calves. J. Dairy Sci. 101:783-793. https://doi.org/10.3168/jds.2017-13247.

Schneider, C. A., W. S. Rasband, and K. W. Eliceiri. 2012. NIH Image to ImageJ: 25 years of image analysis. Nat. Methods 9:671-675. https://doi.org/10.1038/nmeth.2089.

Silper, B. F., A. M. Lana, A. U. Carvalho, C. S. Ferreira, A. P. Franzoni, J. A. Lima, H. M. Saturnino, R. B. Reis, and S. G. Coelho, 2014. Effects of milk replacer feeding strategies on performance, ruminal development, and metabolism of dairy calves. J. Dairy Sci. 97:1016-1025. https://doi.org/10.3168/jds.2013-7201.

Silva, A. L., T. J. DeVries, L. O. Tedeschi, and M. I. Marcondes. 2019. Development of equations, based on milk intake, to predict starter feed intake of preweaned dairy calves. Animal 13:83-89. https:// doi.org/10.1017/S1751731118000666.

Suárez, B. J., C. G. Van Reenen, G. Beldman, J. van Delen, J. Dijkstra, and W. J. Gerrits. 2006a. Effects of supplementing concentrates differing in carbohydrate composition in veal calf diets: I. Animal performance and rumen fermentation characteristics. J. Dairy Sci. 89:4365-4375. https://doi.org/10.3168/jds.S0022 -0302(06)72483-3.

Suárez, B. J., C. G. Van Reenen, W. J. Gerrits, N. Stockhofe, A. M. van Vuuren, and J. Dijkstra. 2006b. Effects of supplementing concentrates differing in carbohydrate composition in veal calf diets: II. Rumen development. J. Dairy Sci. 89:4376-4386. https://doi .org/10.3168/jds.S0022-0302(06)72484-5.

Suárez-Mena, F. X., T. M. Hill, C. M. Jones, and A. J. Heinrichs. 2016. Review: Effect of forage provision on feed intake in dairy calves. Prof. Anim. Sci. 32:383-388. https://doi.org/10.15232/pas .2016-01502.

Sweeney, B. C., J. P. Rushen, D. M. Weary, and A. M. B. de Passillé. 2010. Duration of weaning, starter intake, and weight gain of dairy calves fed large amounts of milk. J. Dairy Sci. 93:148-152. https:/ /doi.org/10.3168/jds.2009-2427.

Tan, D. W., and N. Barker. 2014. Intestinal stem cells and their defining niche. Curr. Top. Dev. Biol. 107:77-107. https://doi.org/10 .1016/B978-0-12-416022-4.00003-2.

Terré, M., L. Castells, M. A. Khan, and A. Bach. 2015. Interaction between the physical form of the starter feed and straw provision on growth and performance of Holstein calves. J. Dairy Sci. 98:1101-1109. https://doi.org/10.3168/jds.2014-8151.

Toullec, R., and P. Guilloteau. 1989. Research into the digestive physiology of the milk-fed calf. Pages 37-55 in Nutrition and Digestive Physiology in Monogastric Farm Animals. E. J. Van Weerdon and J. Huisman, ed.

van Niekerk, J. K., A. J. Fischer-Tlustos, L. L. Deikun, J. D. Quigley, T. S. Dennis, F. X. Suarez-Mena, T. M. Hill, R. L. Schlotterbeck, L. L. Guan, and M. A. Steele. 2020. Effect of amount of milk replacer fed and the processing of corn in starter on growth performance, nutrient digestibility, and rumen and fecal fibrolytic bacteria of dairy calves. J. Dairy Sci. 103:2186-2199. https://doi .org/10.3168/jds.2019-17372.

van Niekerk, J. K., M. Middeldorp, L. Guan, and M. A. Steele. 2021. Preweaning to postweaning rumen papillae structural growth, ruminal fermentation characteristics, and acute-phase proteins in calves. J. Dairy Sci. 104:3632-3645. https://doi.org/10.3168/jds .2020-19003. 
Van Soest, P. J., J. B. Robertson, and B. A. Lewis. 1991. Methods for dietary fiber, neutral detergent fiber, non-starch polysaccharides in relation to animal nutrition. J. Dairy Sci. 74:3583-3597. https:/ /doi.org/10.3168/jds.S0022-0302(91)78551-2.

Wildman, E. E., G. M. Jones, P. E. Wagner, R. L. Boman, H. F. Troutt Jr., and T. N. Lesch. 1982. A dairy cow body condition scoring system and its relationship to selected production characteristics. J. Dairy Sci. 65:495-501. https://doi.org/10.3168/jds S0022-0302(82)82223-6.

Yohe, T. T., H. Schramm, C. L. M. Parsons, H. L. M. Tucker, B. D. Enger, N. R. Hardy, and K. M. Daniels. 2019. Form of calf diet and the rumen. I: Impact on growth and development. J. Dairy Sci. 102:8486-8501. https://doi.org/10.3168/jds.2019-16449.

\section{ORCIDS}

T. T. Yohe $\odot$ https://orcid.org/0000-0001-7029-8322

T. S. Dennis (1) https://orcid.org/0000-0003-3424-5498

L. N. Buss $\odot$ https://orcid.org/0000-0002-5648-2745

J. D. Quigley @ https://orcid.org/0000-0001-8400-8963

T. M. Hill @ https://orcid.org/0000-0003-1304-5016

F. X. Suárez-Mena @ https://orcid.org/0000-0002-1546-5893

K. M. Aragona $\odot$ https://orcid.org/0000-0003-3674-838X

A. H. Laarman $\odot$ https://orcid.org/0000-0003-4805-2793

J. H. C. Costa @ https://orcid.org/0000-0001-9311-4741

M. A. Steele @ https://orcid.org/0000-0001-6941-6205 